\title{
$0 x-2087$

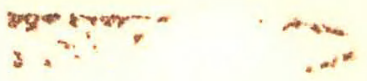 \\ EXPLICIT INVERSES \\ of \\ SOME SPECIAL MATRICES \\ (WITH A FEW COMPUTER PROGRAMS)
}

V.R.R. Uppuluri and B.L. Kirk 
Printed in the United States of America. Available from National Technical Information Service

U.S. Department of Commerce

5285 Port Royal Road, Springfield, Virginia 22161

Price: Printed Copy \$5.50; Microfiche $\$ 2.25$

This report was prepared as an account of work sponsored by the United States Government. Neither the United States nor the Energy Research and Development Administration, nor any of their employees, nor any of their contractors, subcontractors, or their employees, makes any warranty, express or implied, or assumes any legal liability or responsibility for the accuracy, completeness or usefulness of any information, apparatus, product or process disclosed, or represents that its use would not infringe privately owned rights. 


\section{DISCLAIMER}

This report was prepared as an account of work sponsored by an agency of the United States Government. Neither the United States Government nor any agency Thereof, nor any of their employees, makes any warranty, express or implied, or assumes any legal liability or responsibility for the accuracy, completeness, or usefulness of any information, apparatus, product, or process disclosed, or represents that its use would not infringe privately owned rights. Reference herein to any specific commercial product, process, or service by trade name, trademark, manufacturer, or otherwise does not necessarily constitute or imply its endorsement, recommendation, or favoring by the United States Government or any agency thereof. The views and opinions of authors expressed herein do not necessarily state or reflect those of the United States Government or any agency thereof. 


\section{DISCLAIMER}

Portions of this document may be illegible in electronic image products. Images are produced from the best available original document. 
ORNL/CSD-2

$\mathrm{UC}-32$

Contract No. W-7405-eng-26

COMPUTER SCIENCES DIVISION

EXPLICIT INVERSES OF SOME SPECIAL MATRICES

(WITH A FEW COMPUTER PROGRAMS)

V. R. R. Uppuluri and B. L. Kirk

FEBRUARY 1976

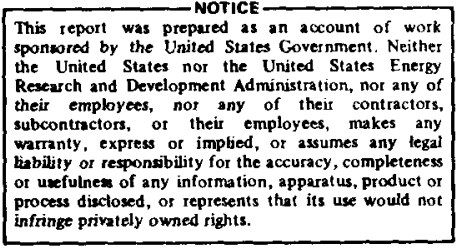

UNION CARBIDE CORPORATION, NUCLEAR DIVISION operating the

Oak Ridge Gaseous Diffusion Plant - Oak Ridge National Laboratory Oak Ridge Y-12 Plant for the

U.S. ENERGY RESEARCH AND DEVELOPMENT ADMINISTRATION 


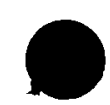


CONTENTS

Abstract . . . . . . . . . . . . . . . . . . . . . 1

Introduction and Summary . . . . . . . . . . . . . . . . . 1

Section I. Tridiagonal Matrices . . . . . . . . . . . . . 3

Section II. The Sherman-Morrison Formula. The Hilbert Matrix.

The Vandermonde Matrix. Other Special Matrices . . . . . . . 13

Section III. Explicit Inverses of Other Forms of Matrices . . . . 17

Acknowledgment . . . . . . . . . . . . . . . . . . 23

Bibliography . . . . . . . . . . . . . . . . . 25

Appendix A . . . . . . . . . . . . . . . . . . . 27

Appendix B ......................... . . 4 41 


\title{
EXPLICIT INVERSES OF SOME SPECIAL MATRICES
}

(WITH A FEW COMPUTER PROGRAMS)

V. R. R. Uppuluri and B. L. Kirk

\begin{abstract}
In this report we present explicit inverses of some classes of special matrices. In Section I, we discuss the tridiagonal matrices. In Section II we discuss an algorithm due to Sherman and Morrison, which is useful in finding the inverse, when an explicit inverse is known for an unperturbed matrix. In Section III we discuss inverses of some patterned matrices. In Appendix A and Appendix B we give computer programs of some of the problems discussed in Sections I, II, and III.
\end{abstract}

\section{INTRODUCTION AND SUMMARY}

Inversion of matrices is an important topic in the theory and app1ications of matrices. In general, it is too much to expect to find the explicit inverse of an arbitrary matrix. For matrices with special structures, at times it is possible to give the general term of the inverses. Such examples of classes of matrices are scattered in literature $[(1),(8),(2),(5)]$, although there are some attempts to bring them together by Graybill (4), Gregory and Karney (5) among others $[(6),(9)]$.

In this report, we will put together some classes of matrices whose explicit inverses are known and make available computer programs for exact computations of the general term of the inverses. In Section I, we present some results in the case of tridiagonal matrices. Some of these are based on Ukita's theorem (which is not widely known) in the case of symmetric tridiagonal matrices. In Section II, we discuss the 
result of Sherman and Morrison (15) and develop a computer program for this purpose. We believe that this is very useful; since in some problems we may know the explicit inverse of a matrix which differs from the original in a few elements, and this program will then enable us to compute the inverse of the desired matrix. The Hilbert matrix, the Vandermonde matrix and a few other special matrices are also discussed in this section. Section III contains a few classes of matrices found in Gregory and Karney (5). Computer programs in Appendix B refer to this section. 
SECTION I. TRIDIAGONAL MATRICES

In this section, we focus our attention on tridiagonal matrices. Let us define a general $n \times n$ tridiagonal matrix by

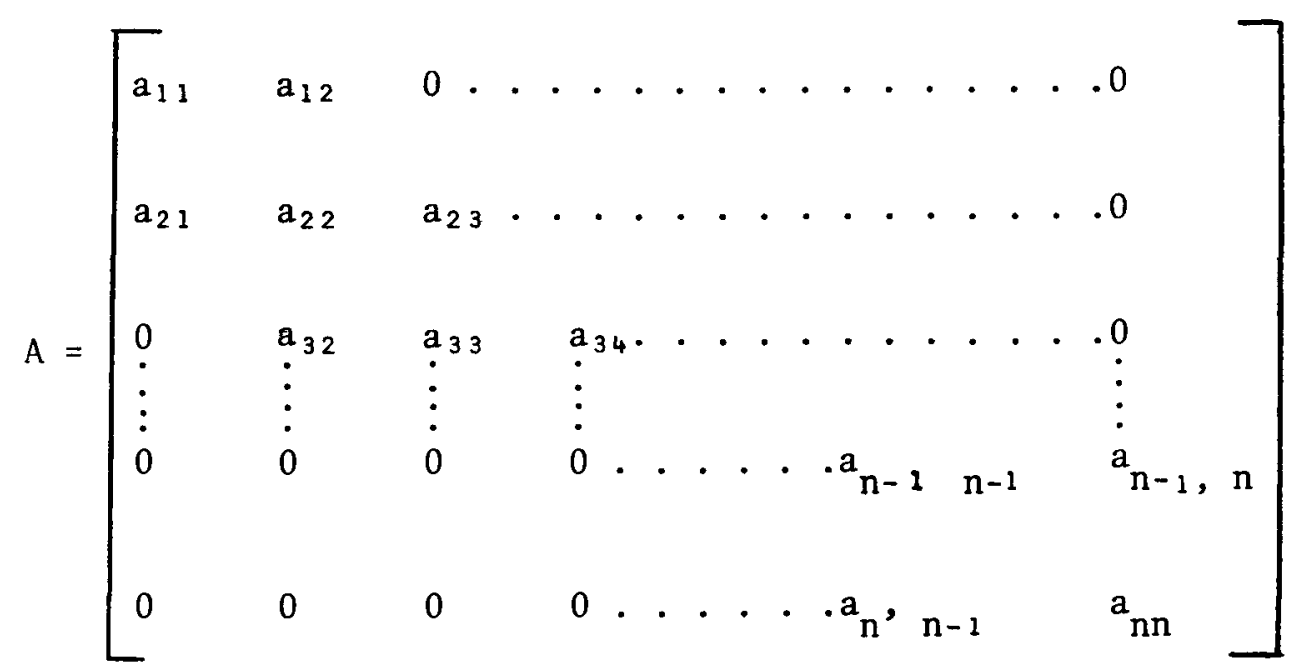

It is known (6) that any arbitrary matrix is similar to a tridiagonal matrix. If we have explicit forms for some special tridiagonal matrices, it may be of value to find the exact inverses.

In the special case when all the diagonal elements are equal to $\mathrm{x}$ $\left(a_{i i}=x, i=1,2, \ldots, n\right)$, and all the off-diagonal elements are equal to each other $\left(a_{i j}=a_{k \ell}=1, i, j, k, \ell=1,2, \ldots, n, i \neq j, k \neq \ell\right)$, it is referred to as a continuant. Continuants are found to be useful in problems in physics and chemistry (13). The $\mathrm{n} \times \mathrm{n}$ continuant

$$
A=\left[\begin{array}{cccccc}
x & 1 & 0 & \ldots & 0 & 0 \\
1 & x & 1 & \ldots & 0 & 0 \\
\vdots & \vdots & \vdots & & \vdots & \vdots \\
0 & 0 & 0 & \ldots & 1 & x
\end{array}\right]
$$


has the following inverse (5),

$$
A^{-1}=\frac{1}{\alpha_{n}}\left[a^{i j}\right] \text {, }
$$

where

$$
a^{i j}=\left\{\begin{array}{l}
\alpha_{i-1} \alpha_{n-i}, \text { if } i=j \\
(-1)^{i+j} \alpha_{i-1} \alpha_{n-j}, \text { if } j>i \\
a^{j i} \text { if } j<i,
\end{array}\right.
$$

and

$$
\begin{aligned}
& \alpha_{0}=1 \\
& \alpha_{1}=x \\
& \alpha_{k}=x \alpha_{k-1}-\alpha_{k-2}, k=2,3, \ldots, n .
\end{aligned}
$$

These results also appear in a note by Vemuri (17), where the matrix was set up as a model of a one-dimensional resistance network.

In Appendix A3, we give a program for the computation of the general term of $\mathrm{A}^{-1}$.

Upon expansion of the formulas $(1.3)-(1.5)$, one can observe that $A^{-1}$ satisfies the conditions of Ukita's theorem. The following statement is a version of this theorem (4).

Theorem: Let $A$ be an $n x n$ symmetric nonsingular matrix with $A_{1} j \neq 0$ for $j=2, \ldots, n$. A necessary and sufficient condition for the inverse of the matrix A to be tridiagonal is the following: 
$(1.6)$

$$
\begin{aligned}
& \frac{a_{2 j}}{a_{1 j}}=\theta_{2}, 2 \leq j \leq n, \\
& \frac{a_{3 j}}{a_{1 j}}=\theta_{3}, 3 \leq j \leq n, \\
& \vdots \\
& \frac{a_{t j}}{a_{1 j}}=\theta_{t}, t \leq j \leq n, \\
& \vdots \\
& \frac{a_{n n}}{a_{1 n}}=\theta_{n}, \quad j=n .
\end{aligned}
$$

The elements of $\mathrm{A}^{-1}$ are:

$$
a^{11}=-\theta_{2}\left(a_{12}-\theta_{2} a_{11}\right)^{-1}
$$

$$
\begin{aligned}
& \left.a^{t t}=-\frac{a_{t-1, t+1}-\theta_{t+1, t-1}}{\left(a_{t-1}, t-\theta_{t} a_{1, t-1}\right)\left(a_{t, t+1}-\theta_{t+1} a_{1} t\right.}\right) \\
& \text { for } t=2,3, \ldots . ., n-1,
\end{aligned}
$$

$$
a^{n n}=\frac{a_{1, n-1}}{a_{1 n}\left(a_{n-1, n}-\theta_{n} a_{1, n-1}\right)} \text {, }
$$

$$
\begin{aligned}
& a^{t, t-1}=a^{t-1, t}=\left(a_{t-1, t}-\theta_{t}{ }_{1, t-1}\right)^{-1}, \\
& \text { for } t=2,3, \ldots . ., n, \\
& a^{i j}=0 \text { if }|i-j|>1 .
\end{aligned}
$$

These formulas are programmed in Appendix A2.

Matrices which satisfy the conditions of Ukita's theorem occur as variance-covariance matrices of problems in mathematical statistics. One such example is the variance-covariance matrix of order statistics for a sample of size $\mathrm{n}$ from an exponential distribution (12): 


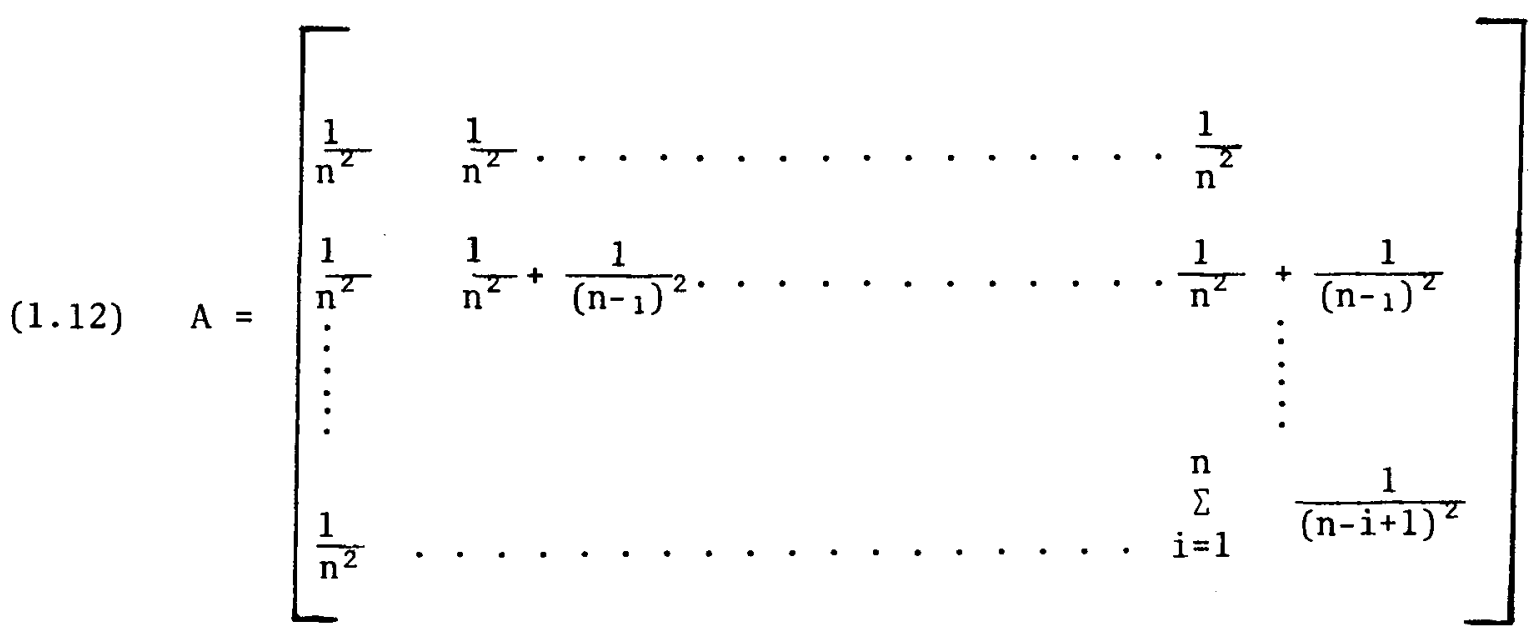

The inverse is given by:

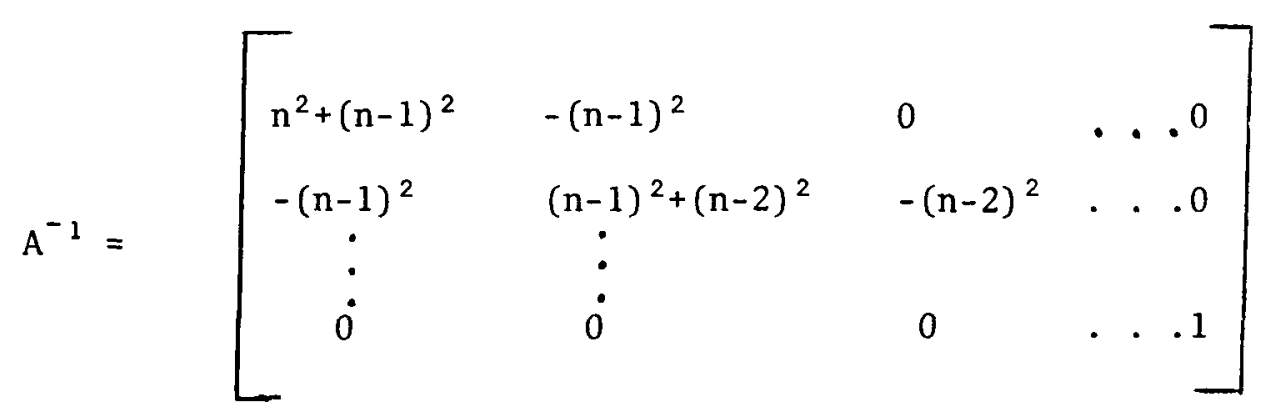

An interesting class of matrices which satisfy Ukita's theorem is given

by

$$
a_{i j}= \begin{cases}c_{j} c_{i}\left(a_{1}+\ldots .+a_{j}\right) \text { if } i>j, \\ c_{j} c_{i}\left(a_{1}+\ldots .+a_{i}\right) \text { if } j \geq i\end{cases}
$$

The inverse of this matrix is given by $A^{-1}=\left(a^{i j}\right)$, where

$$
a^{i j}= \begin{cases}\frac{1}{c_{i}^{2}}\left(\frac{1}{a_{i}}+\frac{1}{a_{i+1}}\right) & \text { if } i=j, \\ -\frac{1}{c_{i-1} c_{i} a_{i}} & \text { if } j=i+1 \text { or } i=j-1, \\ 0 & \text { otherwise. }\end{cases}
$$


If the matrix $A$ is defined by

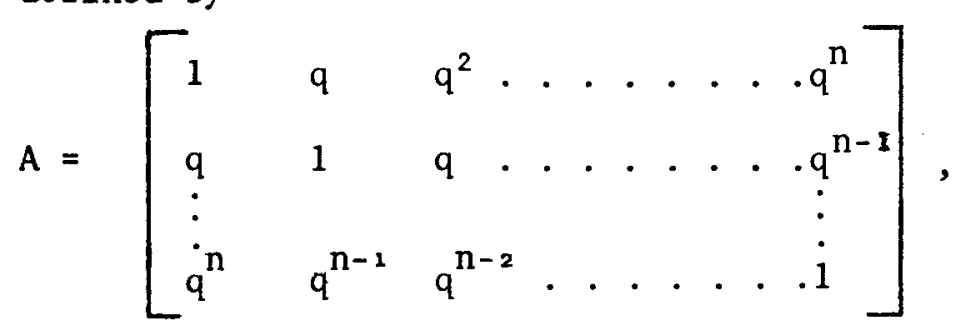

then it is obvious that A satisfies Ukita's theorem again. Explicitly, its inverse is

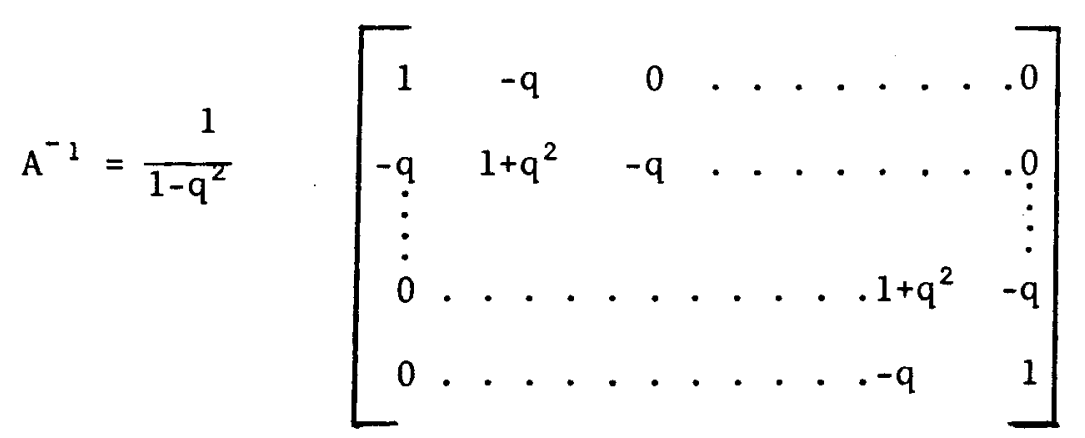

The applicability of Ukita's theorem can also be noticed in the matrix $A=\left(a_{i j}\right), i, j=1, \ldots ., n$, where

$$
a_{i j}= \begin{cases}i / j & \text { if } i \leq j, \\ j / i & \text { if } i>j .\end{cases}
$$

The elements of $A^{-1}$ are supplied by the following formulas:

$$
a^{i j}= \begin{cases}4 i^{3} /\left(4 i^{2}-1\right) & \text { if } i=j, i<n, \\ n^{2} /(2 n-1) & \text { if } i=j=n, \\ -i(i+1) /(2 i+1) & \text { if } j=i+1, \\ -j(j+1) /(2 j+1) & \text { if } i=j+1, \\ 0 & \text { if }|i-j|>1 .\end{cases}
$$


Recently, the inverse for any symmetric tridiagonal matrix was treated by B. Bukhberger and G. A. Emel'yanenko (2). If $\mathrm{A}$ is written as

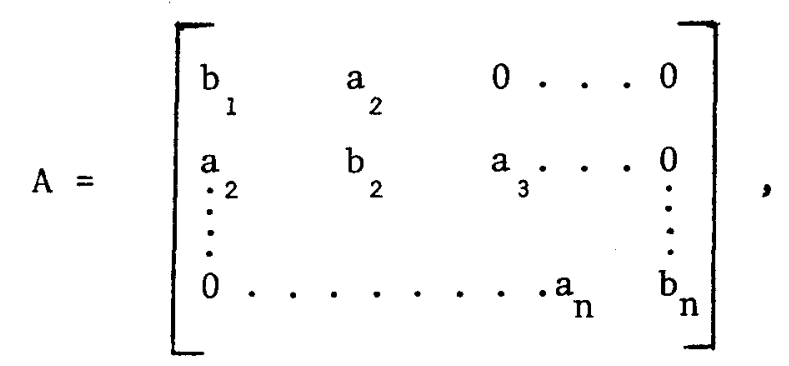

then the inversion of $\mathrm{A}$ is accomplished by means of a decomposition process.

The matrix $\mathrm{A}$ is factored in the following manner (26):

$$
\begin{aligned}
& A=D Q C, \\
& D=\left(d_{i j}\right), \\
& Q=\left(q_{i j}\right), \\
& C=\left(c_{i j}\right),
\end{aligned}
$$

where

$$
\begin{gathered}
d_{i j}=\left\{\begin{array} { c l } 
{ b _ { i } + C _ { i } a _ { i } } & { \text { if } i = j , } \\
{ 0 } & { \text { if } i \neq j , }
\end{array} \left\{\begin{array}{cl}
\frac{a_{i}}{b_{i}+c_{i} a_{i}} & \text { if } i=j+1, j=1 . ., n-1, \\
0 & \text { otherwise. }
\end{array}\right.\right.
\end{gathered}
$$

Denoting by $a^{i j}$ the inverse of the $(i-j)$ th element in $A$, the recursion formulas for obtaining $A^{-1}$ are:

$$
a^{i j}=C_{j+1} a^{i j+1}-a_{j+i}^{-1} \prod_{k=i+1}^{j+1} C_{k},
$$

$$
\text { for } i \leq j, j=n-1, n-2, \ldots ., 1 \text {; }
$$

$$
a^{i n}=\alpha \underset{k=i+1}{n} \quad c_{k}, i=n-1, n-2, \ldots ., 1 \text {; }
$$


(1.26)

$$
a^{n n}=\frac{1}{b_{n}+C_{n}^{a} n}=\alpha
$$

The $C_{i}$ 's in the preceding are defined using the following recursion formulas:

$$
\begin{aligned}
& C_{1}=0 \\
& C_{i}=-\frac{a_{i}}{b_{i-1}+C_{i-1} a_{i-1}}, \quad 2 \leq i \leq n .
\end{aligned}
$$

Explicit formulas for the inverses are available in the case of even order nonsymmetric tridiagonal matrices with zero diagonal elements. The result due to $P$. Clement (3) may be stated as follows.

Let the matrix $A$ be given the form

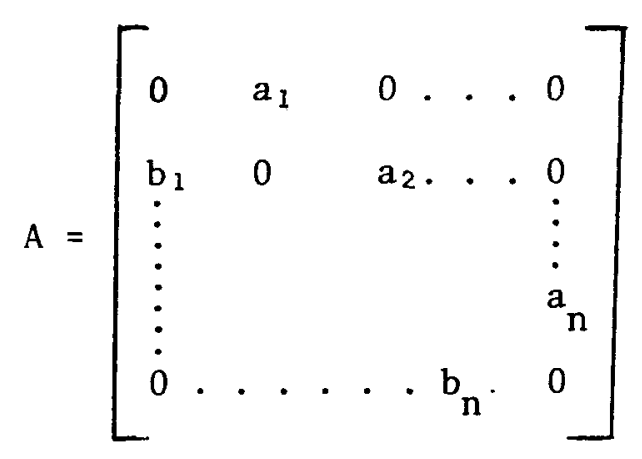

where $\mathrm{n}$ is odd. Then the elements of $\mathrm{A}^{-1}$ are:

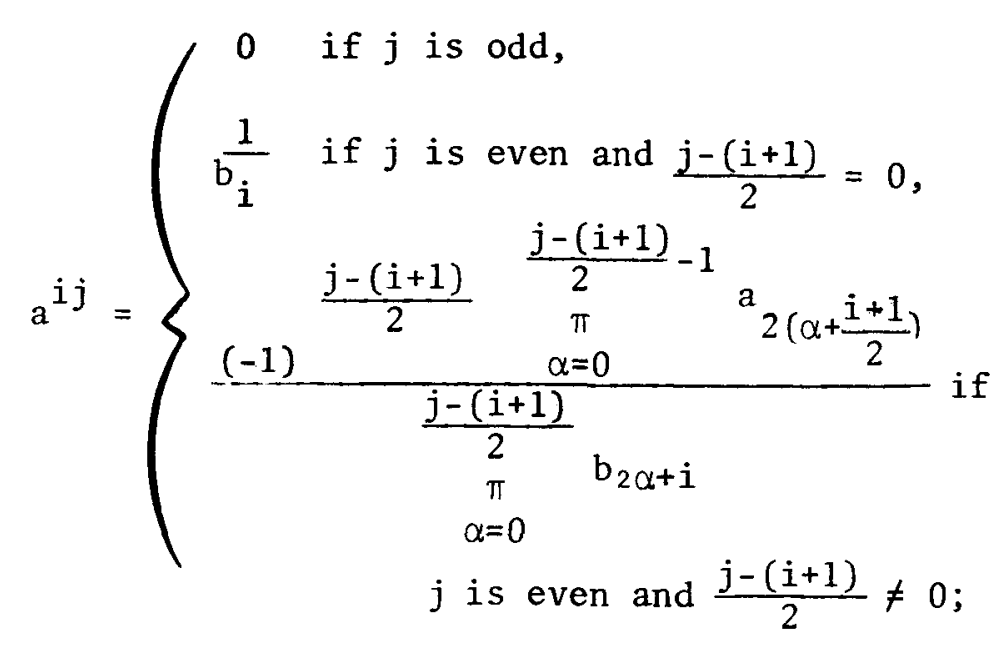


- 
(1.32)

$$
A^{-1}=\left[\begin{array}{ccccccc}
-1 & 1 & 0 & 0 & \ldots & 0 \\
1 & -2 & 1 & 0 & \ldots & 0 \\
0 & 1 & -2 & 1 & \ldots & 0 & 0 \\
\vdots & & & & & \vdots \\
0 & 0 & 0 & 0 & \ldots & 1 \\
0 & 0 & 0 & 0 & \ldots & 1 & -\frac{n-1}{n}
\end{array}\right]
$$

The inverse of the next matrix closely resembles (1.32). Given

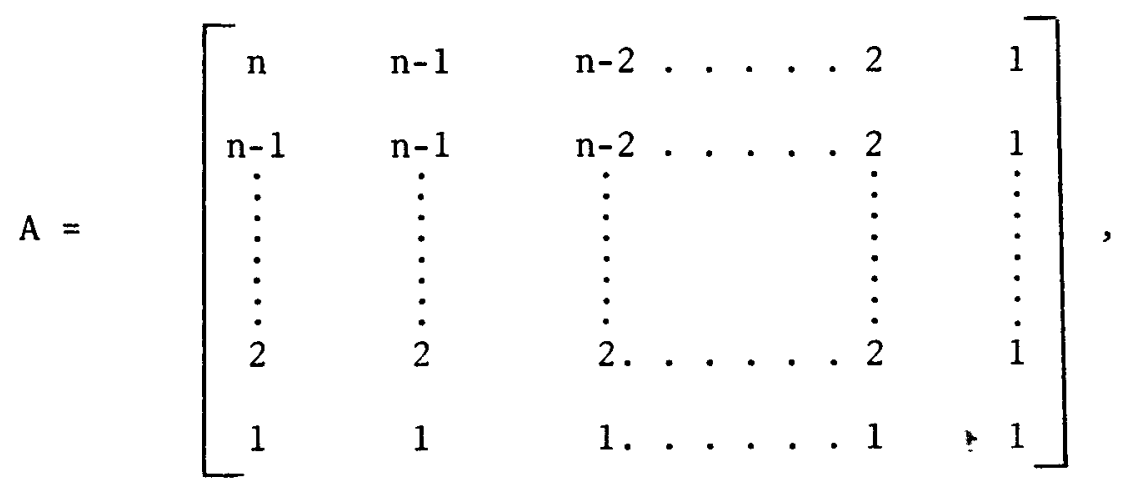

its inverse assumes the form:

$(1.34)$

$$
\mathrm{A}^{-1}=\left[\begin{array}{rrrrrrr}
1 & -1 & 0 & \ldots & 0 & 0 \\
-1 & 2 & -1 & \ldots & 0 & 0 \\
\vdots & \vdots & \vdots & & \vdots & \vdots \\
\vdots & \vdots & \vdots & & \vdots & \vdots \\
0 & 0 & 0 & \ldots & 2 & -1 \\
0 & 0 & 0 & \ldots & -1 & 2
\end{array}\right]
$$




\section{0}


SECTION II. THE SHERMAN-MORRISON FORMULA. THE HILBERT MATRIX. THE VANDERMONDE MATRIX. OTHER SPECIAL MATRICES.

From (1.34), we note that the diagonal elements are all equal to each other with the exception of the first term in the leading diagonal. There is an algorithm due to Sherman and Morrison (15) which is useful in finding the inverse in this case.

Let $A=\left(a_{i j}\right), i, j=1, \ldots ., n ; A^{-1}=\left(a^{i j}\right) ; B=\left(b_{i j}\right)$, where $b_{i j}$ 's denote the elements of $B$ which differ from $A$ in one element, say $b_{R S} ; B^{-1}=\left(b^{i j}\right)$. Further, let

$$
b_{\mathrm{RS}}=\mathrm{a}_{\mathrm{RS}}+\Delta \mathrm{a}_{\mathrm{RS}} \text {. }
$$

Then the set of equations by means of which $B^{-1}$ may be computed from $\Delta a_{R S}$ and $\mathrm{A}^{-1}$ is

$$
b^{r j}=a^{r j}-\frac{a^{r R a^{S j} \Delta a_{R S}}}{1+a^{S R} \Delta a_{R S}}
$$

$\mathrm{r}=1,2, . . ., \mathrm{n} ; \mathrm{j}=1,2, . . ., \mathrm{n} ;$ and $1+\mathrm{a}^{\mathrm{SR}} \mathrm{a}_{\mathrm{RS}} \neq 0$.

The preceding algorithm is applicable where the inverse of the unperturbed matrix A is originally known. This method is also used by Murthy Prabhakar (7), to obtain the explicit inverse of the covariance matrix of a first-order moving average model. A program involving this algorithmic procedure appears in Appendix A6.

An interesting class of matrices with explicit inverses was considered by Chandan Mustafi (8). Let $I_{n}$ be the $n \times n$ identity matrix and $\mathrm{w}_{\mathrm{n}}{ }^{(\mathrm{k})}$ be an $\mathrm{n} \times \mathrm{n}$ matrix whose upper left $\mathrm{k} \times \mathrm{k}$ submatrix consists of elements equal to 1 and remaining elements equal to 0 . Let 


$$
A=I_{n}+\sum_{k=1}^{n} C_{k} W_{n}^{(k)}
$$

with $0<\mathrm{C}_{\mathrm{k}}<\infty(\mathrm{k}=1,2, \ldots, \mathrm{n})$.

Then

$$
A^{-1}=I_{n}-Q
$$

where $Q=\left(q_{i j}\right)$ is an $n \times n$ matrix whose elements have the following form:

$$
q_{i j}= \begin{cases}\lambda_{i} q_{j}, & i \leq j \\ \lambda_{j} q_{i}, & i>j\end{cases}
$$

$i, j=1,2, \ldots, n$.

The quantities $\lambda_{3}, \ldots, \lambda_{n}$, and $q_{1}, \ldots, q_{n}$ are obtained from the following equations:

$$
C_{r-1} \lambda_{r+1}-\lambda_{r}\left(C_{r-1}+C_{r}+C_{r-1} C_{r}\right)+\lambda_{r-1} C_{r}=0
$$

$(\mathrm{r}=2,3, \ldots, \mathrm{n}), \lambda_{1}=1, \lambda_{2}=1+\mathrm{C}_{1}$;

$$
\lambda_{r-1} q_{r}-\lambda_{r} q_{r-1}+C_{r-1}=0
$$

$(r=2,3, \ldots, n)$;

$$
q_{n}=\frac{C_{n-1} C_{n}}{C_{n-1}\left(1+C_{n}\right) \lambda_{n}+C_{n}\left(\lambda_{n}-\lambda_{n-1}\right)} .
$$

The formulas for $\mathrm{A}^{-1}$ are documented in a program contained in Appendix A3.

It is well known that finite segments of the Hilbert matrix are illconditioned and are generally used for test purposes in matrix inversion algorithms. In 1954, Savage and Lukacs (14) presented the Hilbert matrix and its inverse in the following forms: 


$$
\begin{aligned}
A & =\left(\frac{1}{i+j-1}\right), \quad i, j=1, \ldots . ., n, \\
A^{-1} & =\left(a^{i j}\right), \text { where }
\end{aligned}
$$

$$
a^{i j}=\frac{(-1)^{i+j}}{i+j-1} \cdot \frac{(n+i-1) !(n+j-1) !}{[(i-1) !(j-1) !]^{2}(n-i) !(n-j) !}
$$

$i, j=1, \ldots . ., n$.

Again a program for these formulas appears in Appendix A5.

Inverses of Vandermonde matrices appear in curve fitting problems for numerical differentiation and difference equations. The $n \times n$ Vandermonde matrix is defined as (11)

$$
A=\left[\begin{array}{cccc}
1 & 1 & \cdots & 1 \\
\lambda_{1} & \lambda_{2} \cdot \cdots & \lambda_{n} \\
\lambda_{1}^{2} & \lambda_{2}^{2} \cdot \cdots \cdot \lambda_{n}^{2} \\
\vdots & & \\
\lambda_{1}^{n-1} & \lambda_{2}^{n-1} \cdot \cdots & \lambda_{n}^{n-1}
\end{array}\right]
$$

The inverse of A exists iff $\lambda_{1}, \lambda_{2}, \ldots, \lambda_{\mathrm{n}}$ are distinct.

Let $S_{n-j}(i)$ denote the sum of all possible products of the numbers $\lambda_{1}, \ldots . . \lambda_{i-1}, \lambda_{i+1}, \ldots . ., \lambda_{n} \operatorname{taken}(n-j)$ at a time.

The elements of the inverse of $\mathrm{A}$ are given by

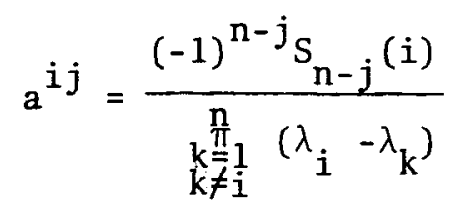

with $S_{0}(i)=1$.

When the matrix $A$ is written as a sum of matrices, B. Noble's tearing formula comes into play (9). That is, if $A=B+C D E$, where $B$ is $n \times n$, 
$C$ is $n \times p, D$ is $p \times p$ and $E$ is $p \times n$, then

$$
A^{-1}=B^{-1}-B^{-1} C\left(D^{-1}+E B^{-1} C\right)^{-1} E B^{-1} \text {. }
$$

An application of the preceding formula is seen in the following. Let

$$
A=B+\lambda e_{i} e_{j}^{T},
$$

where $e_{i}$ 's are unit vectors. Then from the inverse formula (1.47),

$$
A^{-1}=B^{-1}-\frac{\lambda p_{i} q_{j}^{T}}{1+\alpha_{j i}}
$$

$\alpha_{j i}$ is the $(j, i)$ th element of $B^{-1}, p_{i}=B^{-1} e_{i}$,

the ith column of $\mathrm{B}^{-1}$,

$q_{j}{ }^{T}=e_{j}{ }^{T} B^{-1}$, the $j$ th row of $A^{-1}$ 


\section{SECTION III. EXPLICIT INVERSES OF OTHER FORMS OF MATRICES}

Another useful source of examples of matrices with explicit inverses is Chapter III in the book by R. T. Gregory and David L. Karney (5). We selected the following examples and present computer programs in Appendix B.

EXAMPLE I. (Appendix B1)

Let $A=\left(a_{i j}\right), a_{i j}=n-|i-j|$.

Then $A^{-1}=\left(a^{i j}\right)$ is given by

$$
a^{i j}=\left\{\begin{array}{cl}
\frac{n+2}{2 n+2}, & \text { if } i=j=1 \text { or } i=j=n \\
I, & \text { if } i=j \text { and } 1<i<n \\
-\frac{1}{2}, & \text { if }|i-j|=1 \text { and } n \neq 2 \\
-\frac{1}{3}, & \text { if }|i-j|=1 \text { and } n=2 \\
\frac{1}{2 n+2}, & \text { if }|i-j|=n-1 \neq 1 \\
0, & \text { if } I<|i-j|<n-1 .
\end{array}\right.
$$

EXAMPLE 2. (Appendix B2)

Let $A=\left(a_{i j}\right)$, where

Then $A^{-1}=\left(a^{i j}\right)$, where

$$
\begin{aligned}
& a_{1 j}=1, j=1,2, \ldots . ., n, \\
& a_{i j}=\frac{1}{i+j-1}, i=2,3, . . ., n, j=1,2, \ldots ., n .
\end{aligned}
$$

$$
\begin{aligned}
& a^{i 1}=(-1)^{n-i}\left(\begin{array}{c}
n+i-1 \\
i-1
\end{array}\right)\left(\begin{array}{c}
n \\
i
\end{array}\right), i=1,2, \ldots, n, \\
& a^{i, j+1}=(-1)^{i-j}\left(\begin{array}{c}
i+j \\
j
\end{array}\right)\left(\begin{array}{c}
i+j-1 \\
j-1
\end{array}\right)\left(\begin{array}{c}
n+i-1 \\
i+j
\end{array}\right)\left(\begin{array}{c}
n+j \\
i+j
\end{array}\right) i
\end{aligned}
$$

for $i=1,2, \ldots . ., n, j=1,2, \ldots . ., n-1$. 
EXAMPLE 3. (Appendix B3)

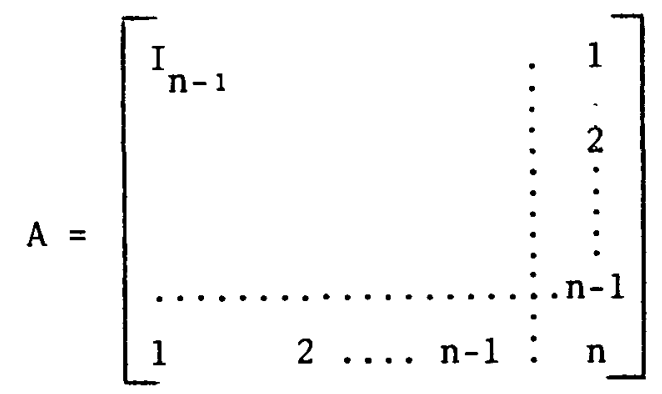

$$
\begin{aligned}
& A^{-1}=\left(a^{i j}\right) \text {, where } \\
& \mathrm{a}^{\mathrm{ii}}=1-\mathrm{ki}^{2}, 1 \leq \mathrm{i} \leq \mathrm{n}-1 \\
& a^{n n}=-k \\
& a^{i j}=-k i j \text {, if } i \neq j, 1 \leq i \leq n-1 \text {, and } 1 \leq j \leq n-1 \\
& a^{i n}=a^{n i}=k i, 1 \leq i \leq n-1 \\
& \text { and } k=\frac{6}{n(n+1)(2 n-5)}
\end{aligned}
$$

EXAMPLE 4. (Appendix B4)

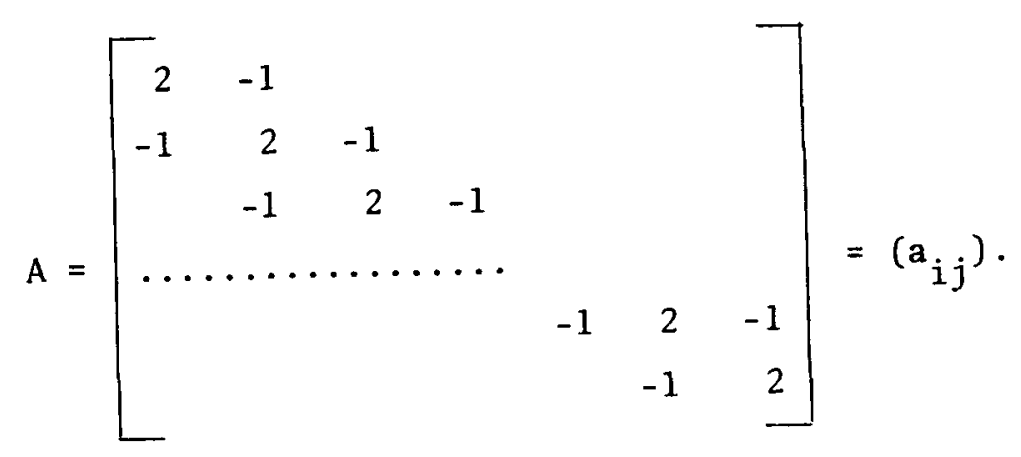

$$
\begin{aligned}
& A^{-1}=\left(a^{i j}\right) \text {, where } \\
& a^{i j}= \begin{cases}\frac{i(n-i+1)}{n+1}, & \text { if } i=j \\
\frac{a^{i, j-1}-i}{n+1}, & \text { if } j>i \\
\frac{a^{j i}}{n+1}, & \text { if } j<i\end{cases}
\end{aligned}
$$


EXAMPLE 5. (Appendix B5)

$$
\begin{aligned}
& A=\left[\begin{array}{ccccccc}
\mathrm{x}+\mathrm{b} & 1 & & & & & \\
1 & \mathrm{x} & 1 & & & & \\
& 1 & \mathrm{x} & 1 & & & \\
\ldots \ldots & \ldots \ldots \ldots & & & \\
& & & & 1 & \mathrm{x} & 1 \\
& & & & 1 & \mathrm{x}+\mathrm{a}
\end{array}\right] \\
& A^{-1}=\left(a^{i j}\right) \text {, where } \\
& a^{i j}=a^{j i}=\frac{(-1)^{i+j} r_{j-1} s_{n-i}}{(x+a) r_{n-1}-r_{n-2}}, j \geq i,
\end{aligned}
$$

where

$$
\begin{aligned}
& r_{0}=1 \\
& r_{1}=x+b \\
& r_{k}=x r_{k-1}-r_{k-2}, k=2,3, \ldots . ., n-1
\end{aligned}
$$

and

$$
\begin{aligned}
& s_{0}=1 \\
& s_{1}=x+a \\
& s_{k}=x s_{k-1}-s_{k-2}, k=2,3, \ldots ., n-1
\end{aligned}
$$

EXAMPLE 6. (Appendix B6)

$$
A=\left(a_{i j}\right), \quad a_{i j}=|i-j| .
$$




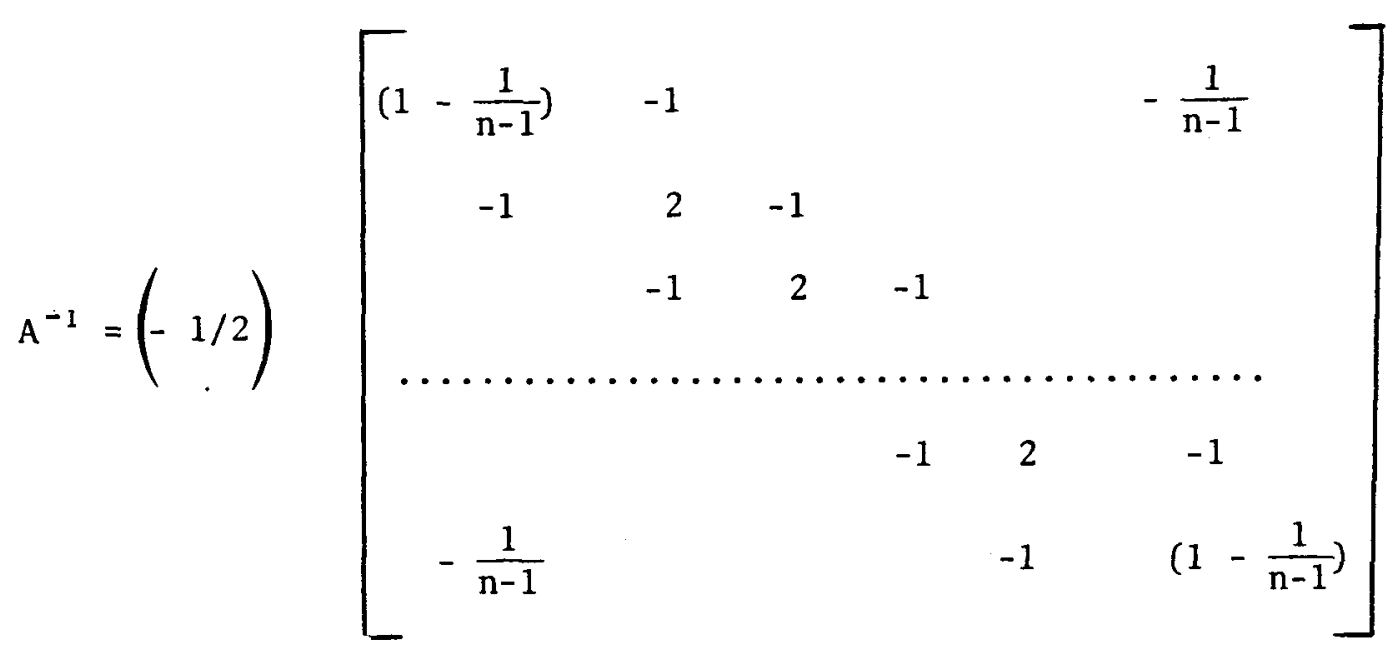

EXAMPLE 7. (Appendix B7)

$$
\begin{aligned}
& A=\left(a_{i j}\right), \text { where } \\
& a_{i j}=\left\{\begin{array}{lll}
1 & \text { if } & j \geq i \\
a_{j} & \text { if } & j<i .
\end{array}\right.
\end{aligned}
$$

Then

$$
\begin{aligned}
& A^{-1}=\left(a^{i j}\right) \text {, where } \\
& a^{i j}= \begin{cases}\frac{1}{1-a_{i}} \text { if } i=j, i \neq n, \\
\frac{-1}{1-a_{i}} \text { if } j=i+1, i \neq n, \\
\left(a_{j-1}-a_{j}\right) /\left[\left(1-a_{j}\right)\left(1-a_{j-1}\right)\right] \text { if } i=n, j \neq 1, n, \\
-a_{1} /\left(1-a_{1}\right) \text { if } i=n, j=1, \\
1 /\left(1-a_{n-1}\right) \text { if } i=j=n, \\
0 \quad \text { otherwise. }\end{cases}
\end{aligned}
$$


EXAMPLE 8. (Appendix B8)

$A=\left[\begin{array}{ccccc}(x+y) & y & y & . & y \\ y & (x+y) & y & . & \cdot y \\ \ldots \ldots & \ldots & \ldots & \ldots \\ y & y & y & . & (x+y)\end{array}\right]$

If $A^{-1}=\left(a^{i j}\right)$, then

$$
a^{i j}=\frac{\delta_{i j}(x+n y)-y}{x(x+n y)}
$$

where $\delta_{i j}$ is the Kronecker delta. 
0

0 


\section{ACKNOWLEDGMENT}

We wish to thank Mr. J. A. Carpenter for his help in the technical aspects of this report. Some of the references used in this report were collected in the past by J. A. Carpenter and V. R. R. Uppuluri. 
-

0 


\section{BI BLIOGRAPHY}

(1) E. L. Allgower, "Exact Inverses of Certain Band Matrices," Numer. Math. 21 (1973), pp. 279-284.

(2) B. Bukhberger and G. A. Emel'yanenko, "Methods of Inverting Tridiagonal Matrices," USSR Comp. Math. and Math. Physics, Volume 13, No. 3 (1973), pp. 10-20.

(3) Paul A. Clement, "A Class of Triple Diagonal Matrices for Test Purposes," Siam Review, Vo1. I, No. 1 (1959), pp. 50-52.

(4) Franklin A. Graybi11, Introduction to Matrices with Applications in Statistics, Belmont, California: Wadsworth Publishing Co., 1969.

(5) R. T. Gregory and David L. Karney, A ColZection of Matrices for Testing Computational AZgorithms, New York: John Wiley and Sons, 1969 .

(6) Alston S. Householder, The Theory of Matrices in Numerical Analysis, New York: Blaisde11 Publishing Co., 1964.

(7) D. N. Murthy Prabhakar, "On the Inverse of the Covariance Matrix of a First Order Moving Average," SANKHA: The Indian Journal of Statistics, Vol. 36, Series A, Pt. 2, pp. 223-225 (1974).

(8) Chandan Mustafi, "The Inverse of a Certain Matrix, With an Application," Ann. Math. Stat. 38, p. 1289 (1967).

(9) Ben Noble, Applied Linear Algebra, New Jersey: Prentice-Hall, Inc., 1969 . Lars Rehnquist, "Inversion of Certain Symmetric Band Matrices," BIT 12, pp. 90-98 (1972). 
(11) B. C. Roy and A. K. Choudhury, "On the Determination of the Inverse of a Vandermonde Matrix," Am. J. Control, Vol. 12, No. 3, pp. 525-527 (1970)

(12) S. N. Roy and A. E. Sarhan, "On Inverting A Class of Patterned Matrices," Biometrika, Vo1. 43, pp. 227-231 (1960).

(13) D. E. Rutherford, "Some Continuent Determinants Arising in Physics and Chemistry," Proc. Roy. Soc. Edinburgh, Sect. A, Vol. 62, pp. 229-236 (1945) .

(14) I. R. Savage and E. Lukacs, "Tables of Inverses of Finite Segments of the Hilbert Matrix," NBS APPLIED MATH, Series 39, pp. 105-108 (1954)

(15) Jack Sherman and Winifred Morrison, "Adjustment of an Inverse Matrix Corresponding to a Change in One Element of a Given Matrix," Ann. Math. Stat. 21, pp. 124-126 (1950).

(16) Thomas C. T. Ting, "A Method of Solving a System of Linear Equations Whose Coefficients Form a Tridiagonal Matrix," Quart. App Z. Math., Vo1. 22, No. 2, pp. 105-116.

(17) V. Vemuri, "On a Property of a Class of Resistance Networks with a Ladder Structure," Int. J. EZectronics, Vol. 25, 197-199 (1968). 
APPENDIX A 


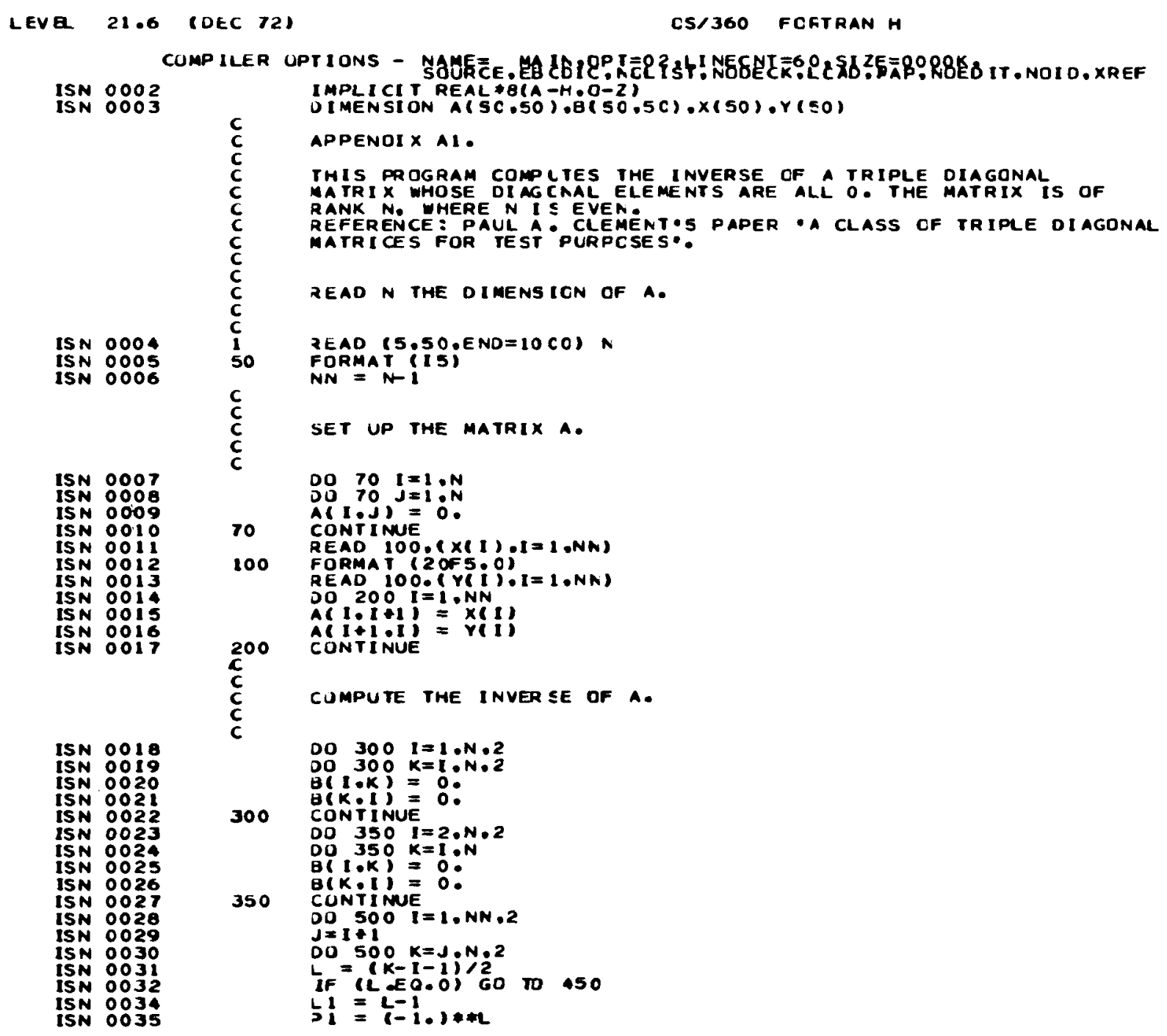




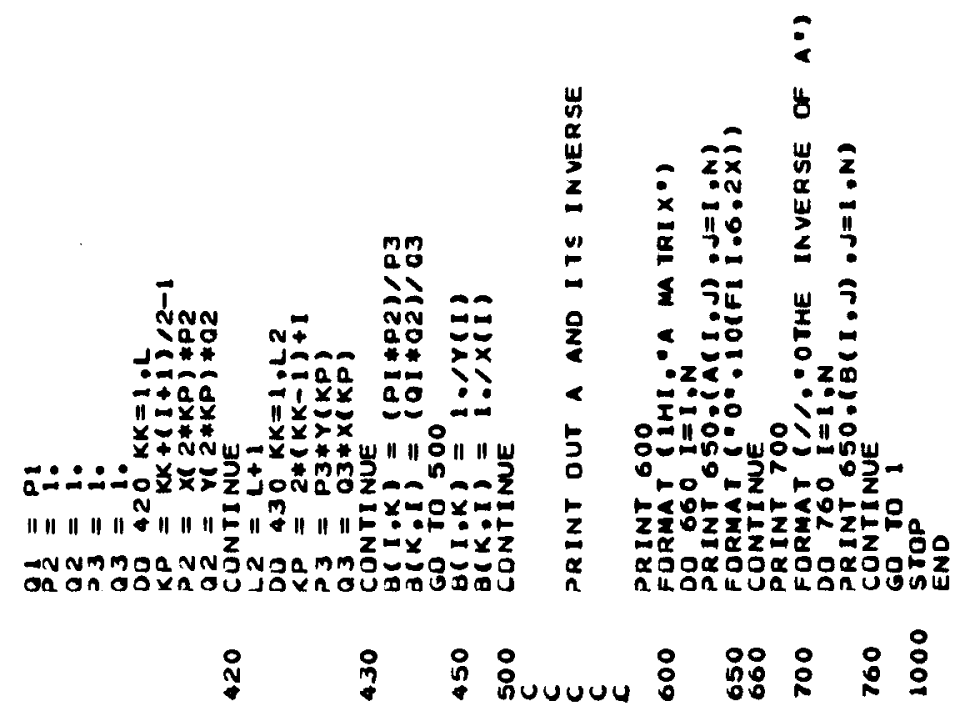

ONDOOFNM+nONDGO-NM+nOR mmmm t+ + + +

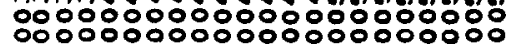
Z2Z2ZZZ2Z2Z2Z2222222Z2

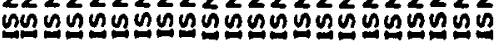

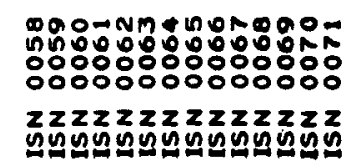




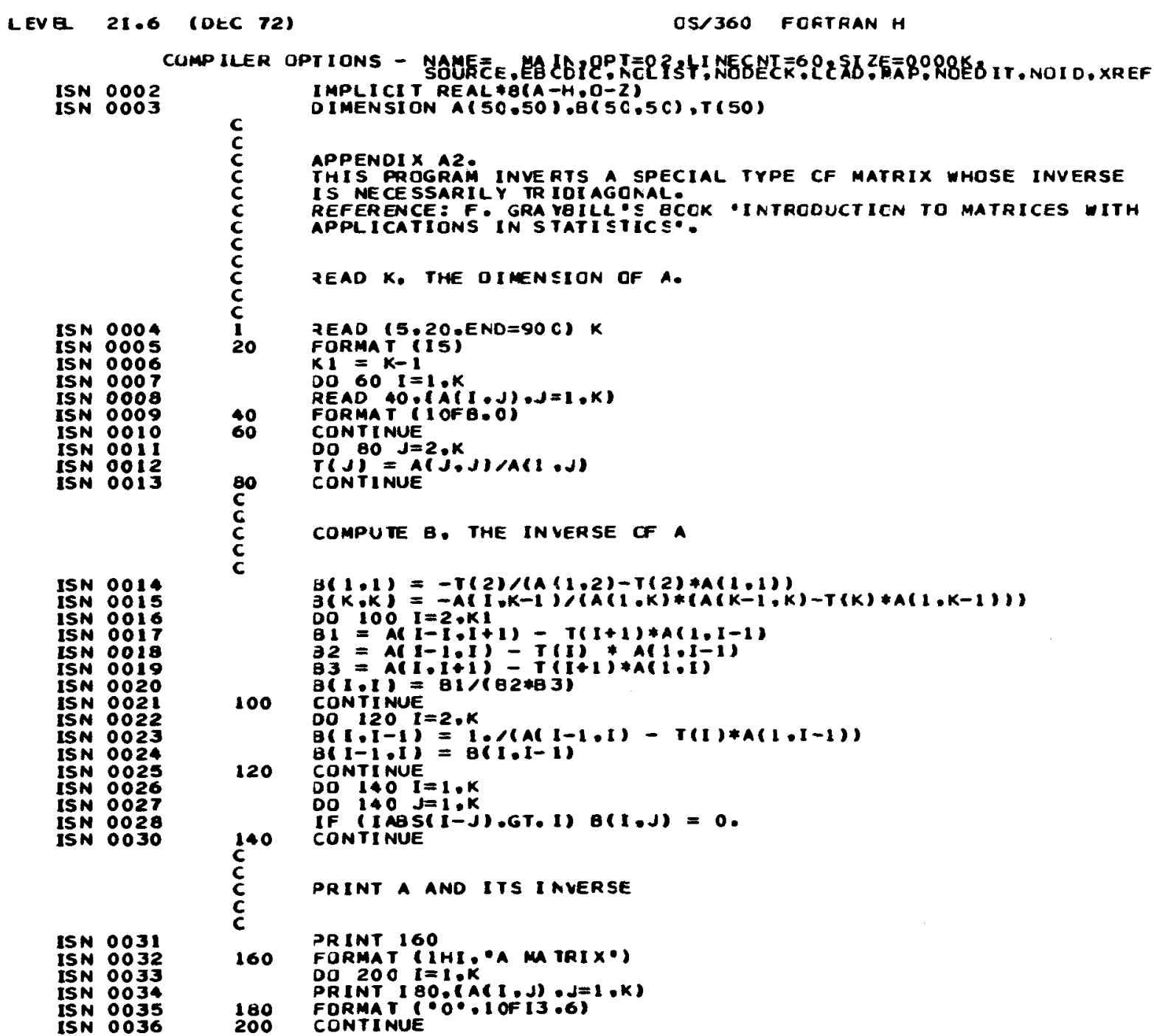

ISN 0031

ISN :0

ISN 0034

IS N 0035

PRINT 160

FORMAT (IHI, "A MU TRIX・)

PRINT I BO.:iA $(I, J), J=1, K)$

180
200

FORMA TUNTE $(00.1 \text { of } 13: 6)^{\circ}$ 
ISN $: 037$

ISN 0030

ISN OOA

IS $\operatorname{Iogh}^{-15}$

220 FREMTIT2O

DO $240 \quad I=1, k$,

240 CONTINUE

SOO STOP 


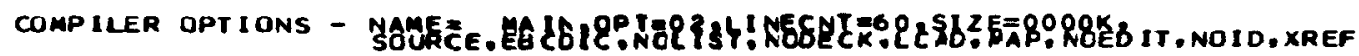

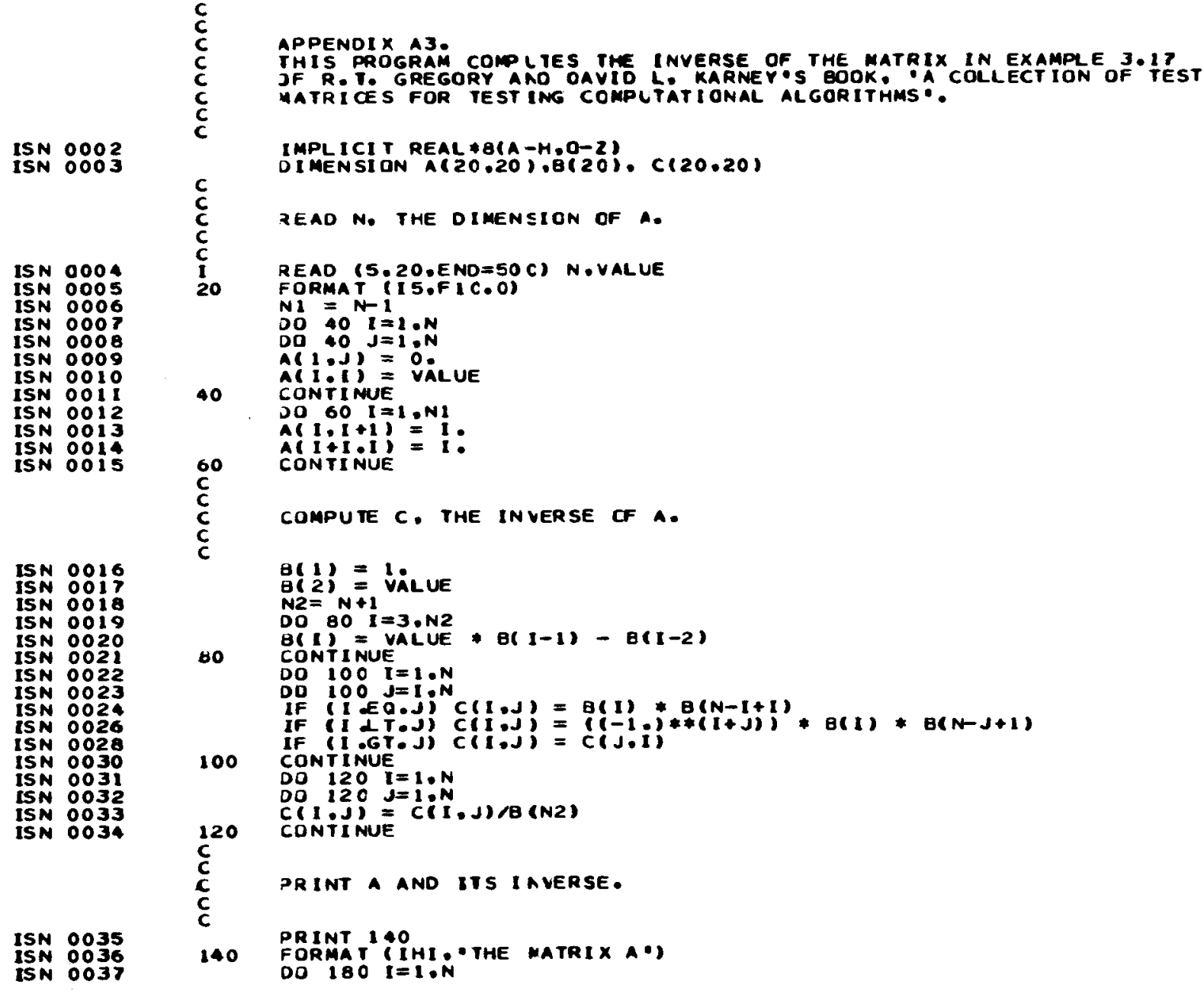

ISN 0035
ISN :036
ISN 0037 TEAO N. THE DIMENSION OF A.

\section{REAO $(5 \cdot 20 . E N D=50 \mathrm{C})$ N.VALUE}

FORMAT $(15, F 1 C \cdot 0)$

$N_{1}=N^{-1}$

Do $40 \quad I=2 . N$

$A(1, J)=0$.

40

Al1:( = VALUE

SONTINUE

A( $1+1+1)=1$ :

60
$c$
$c$
$c$
$c$
$c$

COMPUTE C. THE INVERSE CF A.

昌 $\left(\begin{array}{l}1 \\ 2\end{array}\right) \equiv$ ViLUE

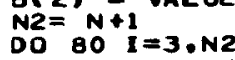

BO $801=3$.N2 $B(1-1)-B(1-2)$

BO CONTINUE

Do $100 \quad J=1 . N$

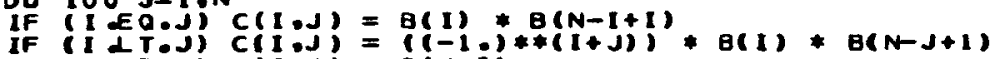

100

IF (I.GT.J) $C(1, J)=C(J . i)$

DO $120 \mathrm{I}=1$. N

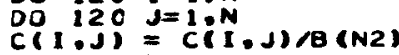

120 Continue

120
$C$
$C$
$C$

PRINT 1 *0

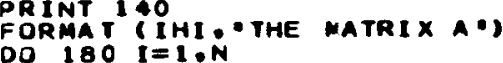




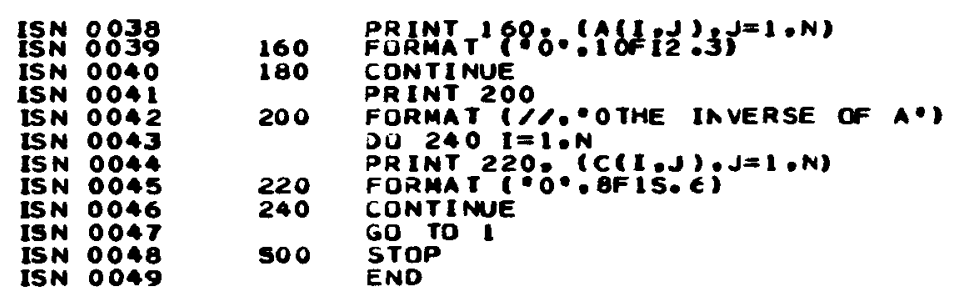




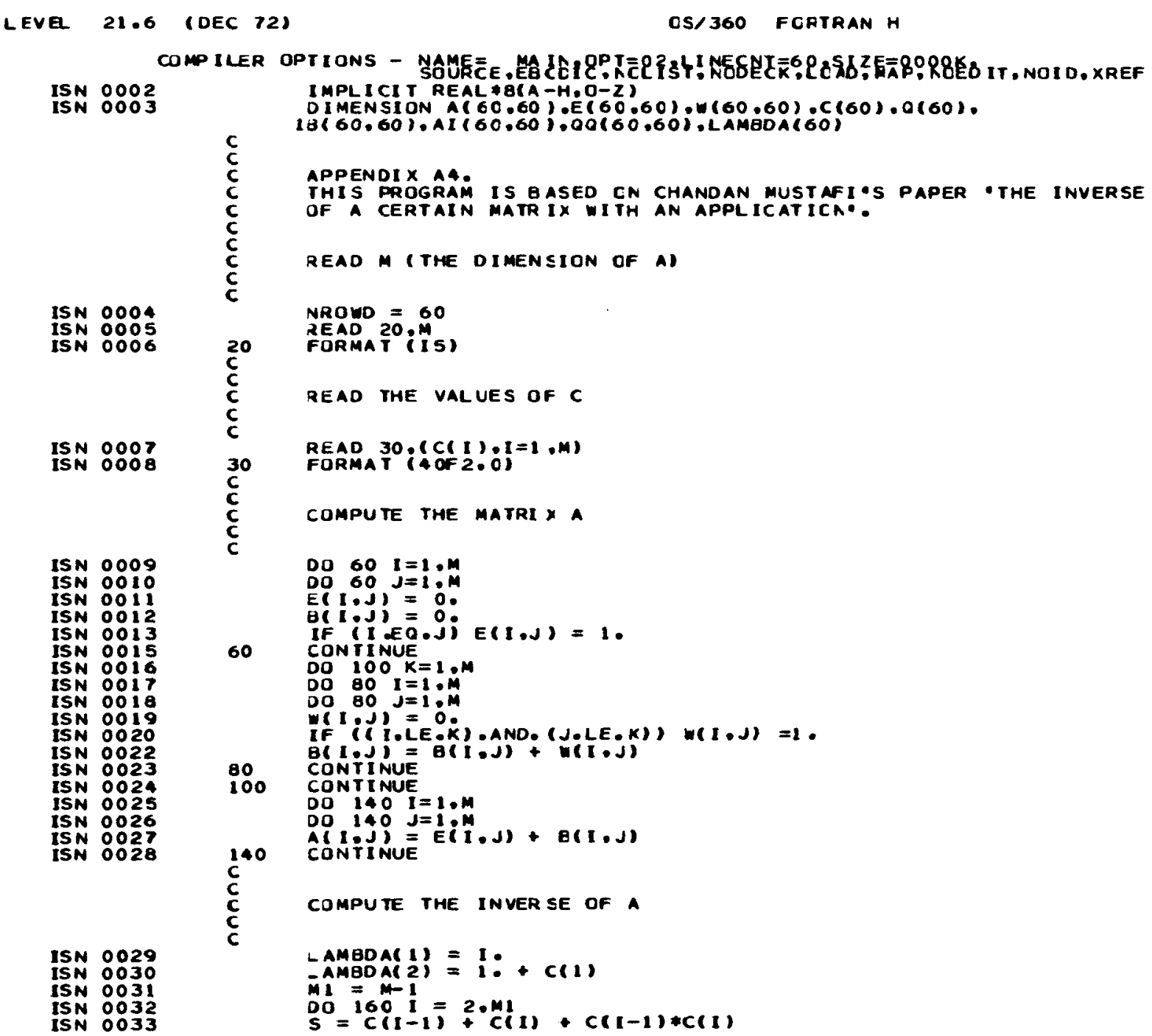

ISN 0029

ISN 0031

ISN 0033

NROMD $=60$

20 FORMATIISI

read the values of C

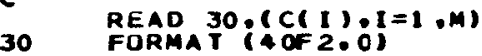

COMPUTE THE MATRI $\times A$

c

60

Do $60 \quad I=1 ; M$

$E(1, J)=0$.

(1)

DO $100 \mathrm{~K}=1, \mathrm{M}$

Do $80 \mathrm{~J}=1 ; M$

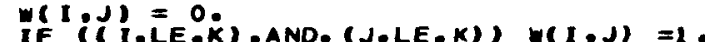

$B(1, J)=B(1, j)+(n)(10 j)$

CONTINUE

100

CONTINUE

DO $140 \mathrm{I}=1 . \mathrm{M}$

140 Cóntinue

$c$
$\mathbf{c}$
$\mathbf{c}$
$\mathbf{c}$
$\mathbf{c}$

COMPUTE THE INVER SE OF A

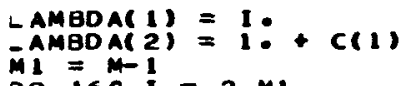

${ }_{S O}=1601=2 . M 1$ 

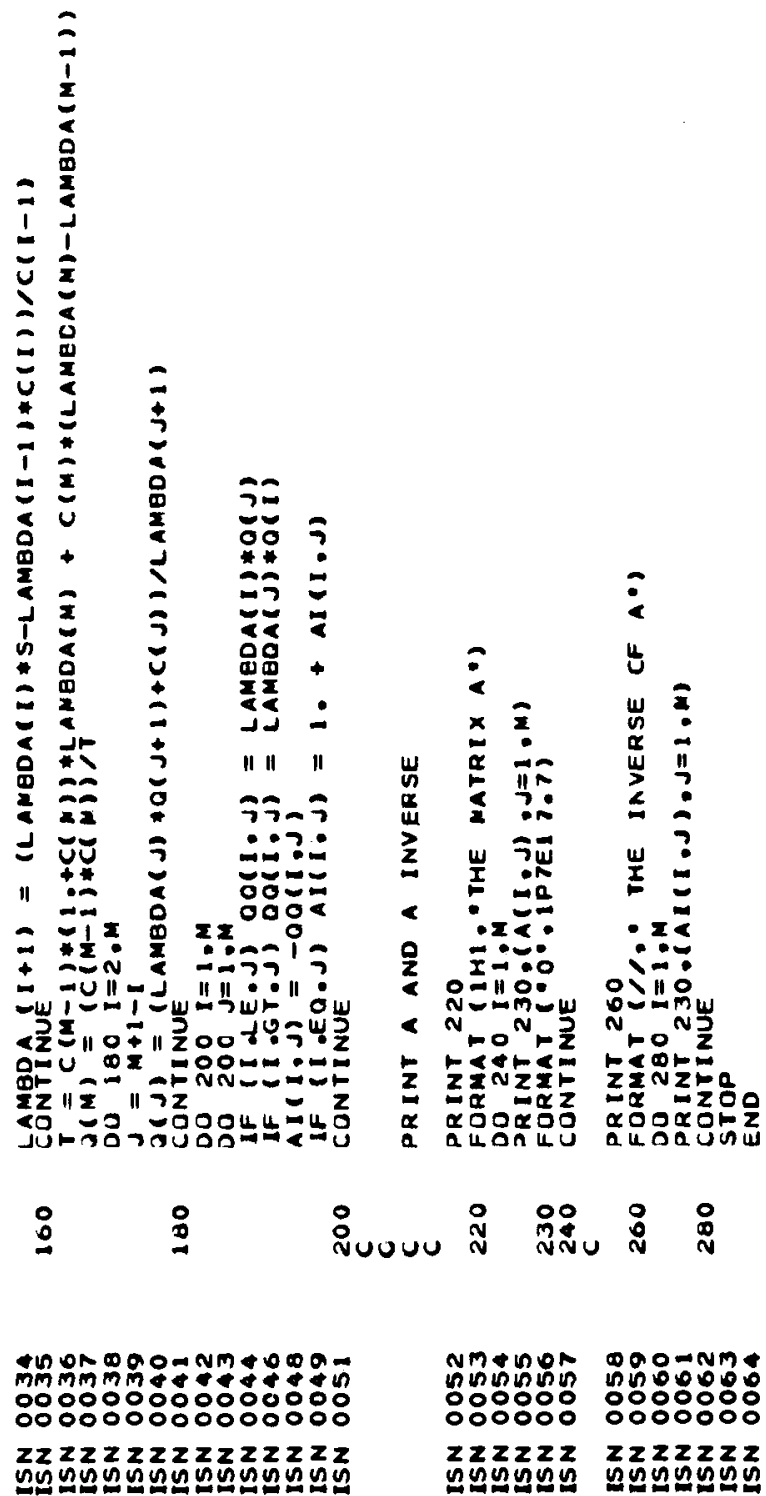


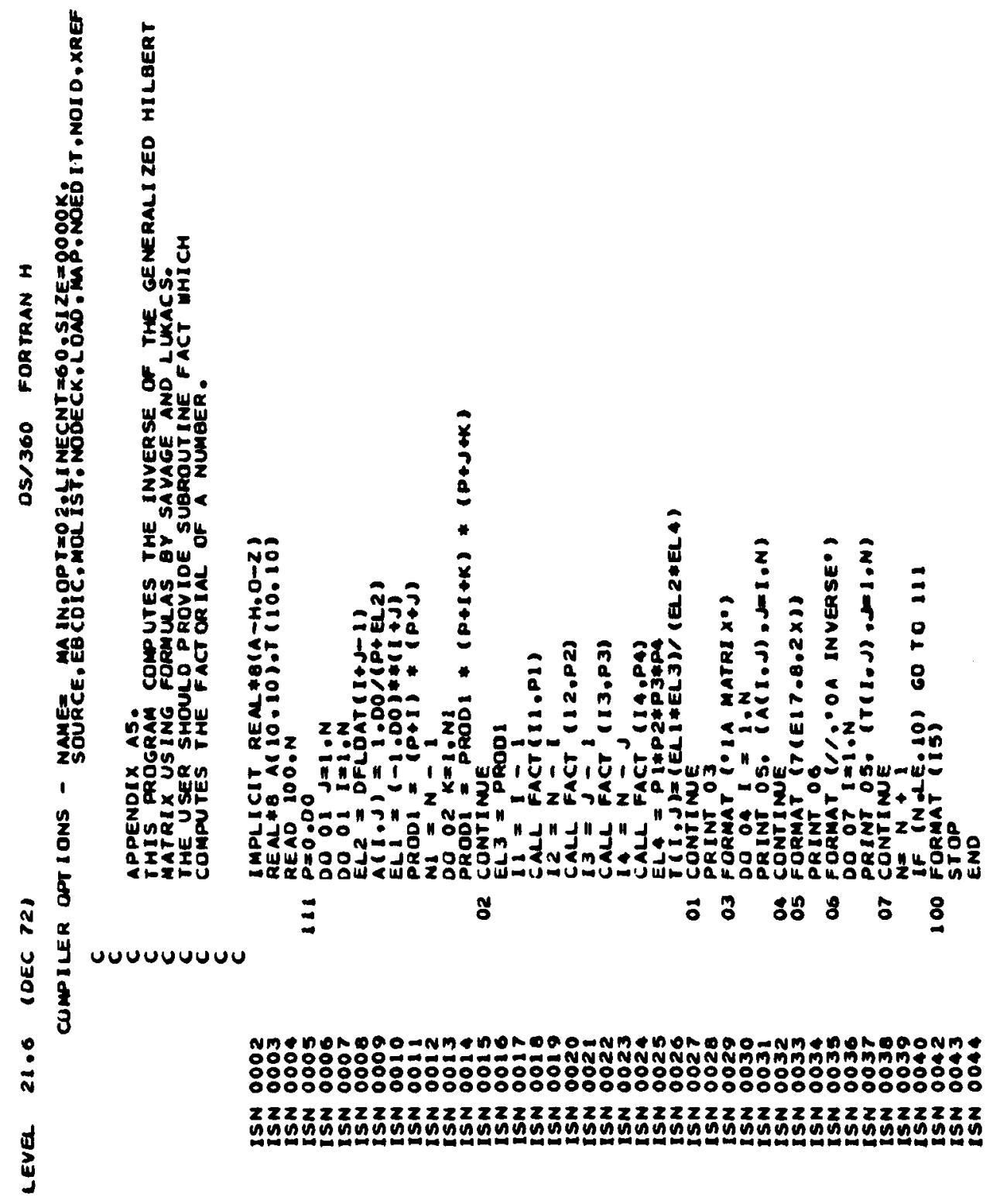




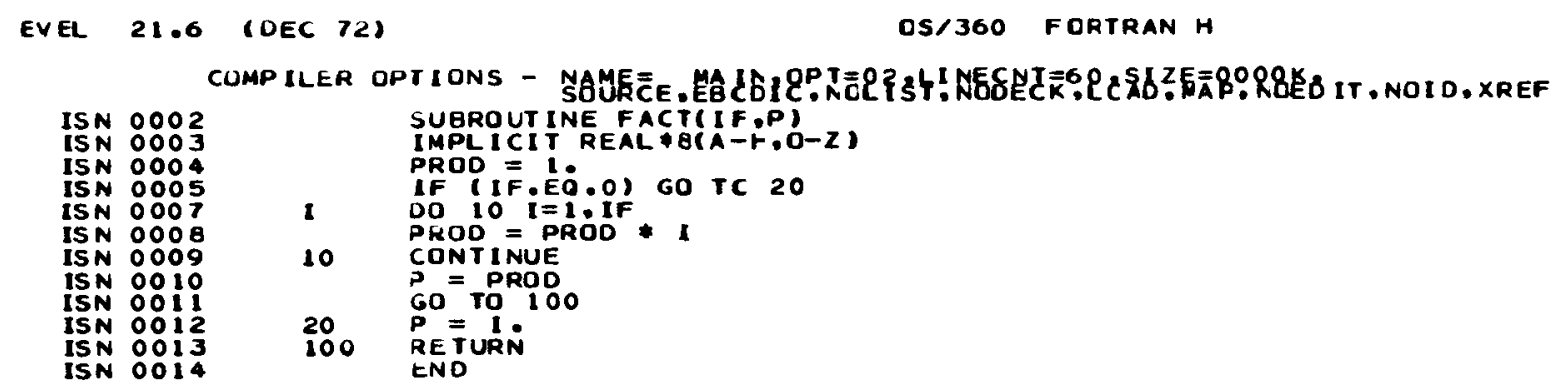




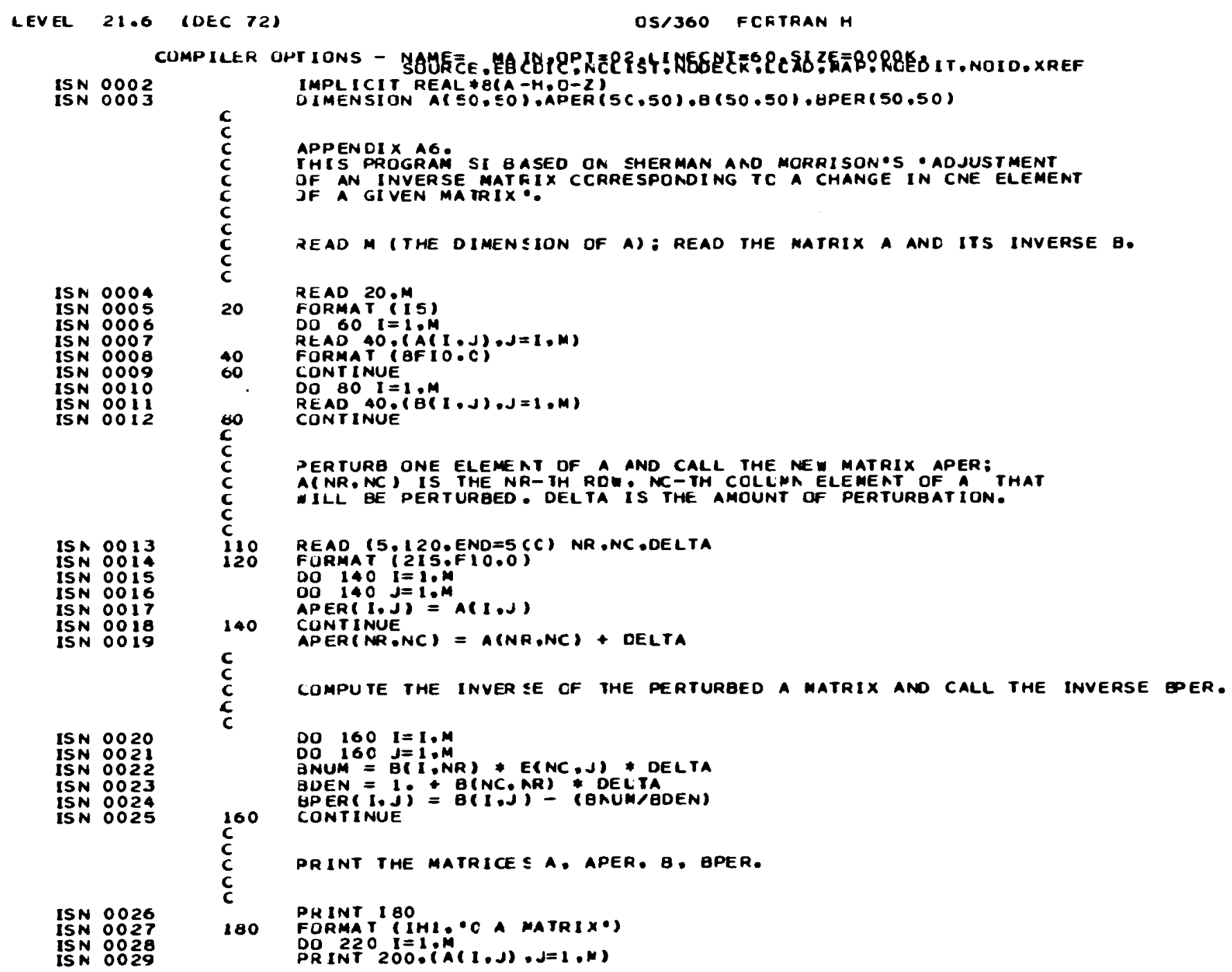

ISA :OO13

ISN 0015

ISN OOIG

ISN OOI

IS OOIS

ISN 0020

ISN OO2

ISN 0023

ISN 0024

READ $20 . M$ MORMAT (IS)

20 FORMAT $(I 5)$

40 READ 40 : (AP $(I \cap J) \cdot J=1 \cdot M)$

60 CONT TNUE

SO READ $40,(B(1, J), J=1, M)$

PERTURB ONE ELEMENT DF A ANO CALL THE NEW MATRIX APER:

A NR. NC, IS THE NR- IH ROE MC-TH COLCWA ELEMEAT OF A THAT

10 READ $(5,120, E N D=5(C)$ NR.NC . DELTA

DO $140 \quad I=1 . M$

APER $(1, J)=A(1, J)$

CONTINUE

C APER(NR,NC) = A(NR,NC) + DELTA

c

compute the inverse of the perturbed a matrix ano call the inverse goer.

DO $160 \quad I=1, M$

BNUM = B(I,NR) * E(NC,J) * DELTA

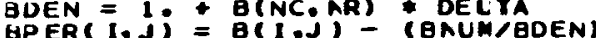

160 CONTINUE

PRINT THE MATRICES A, APER, B, BPER.

ISN 0026

ISN 0028

C

PRINT 180

Hito MATRIX

DRINT $200, i A(1, J), J=1, N)$ 


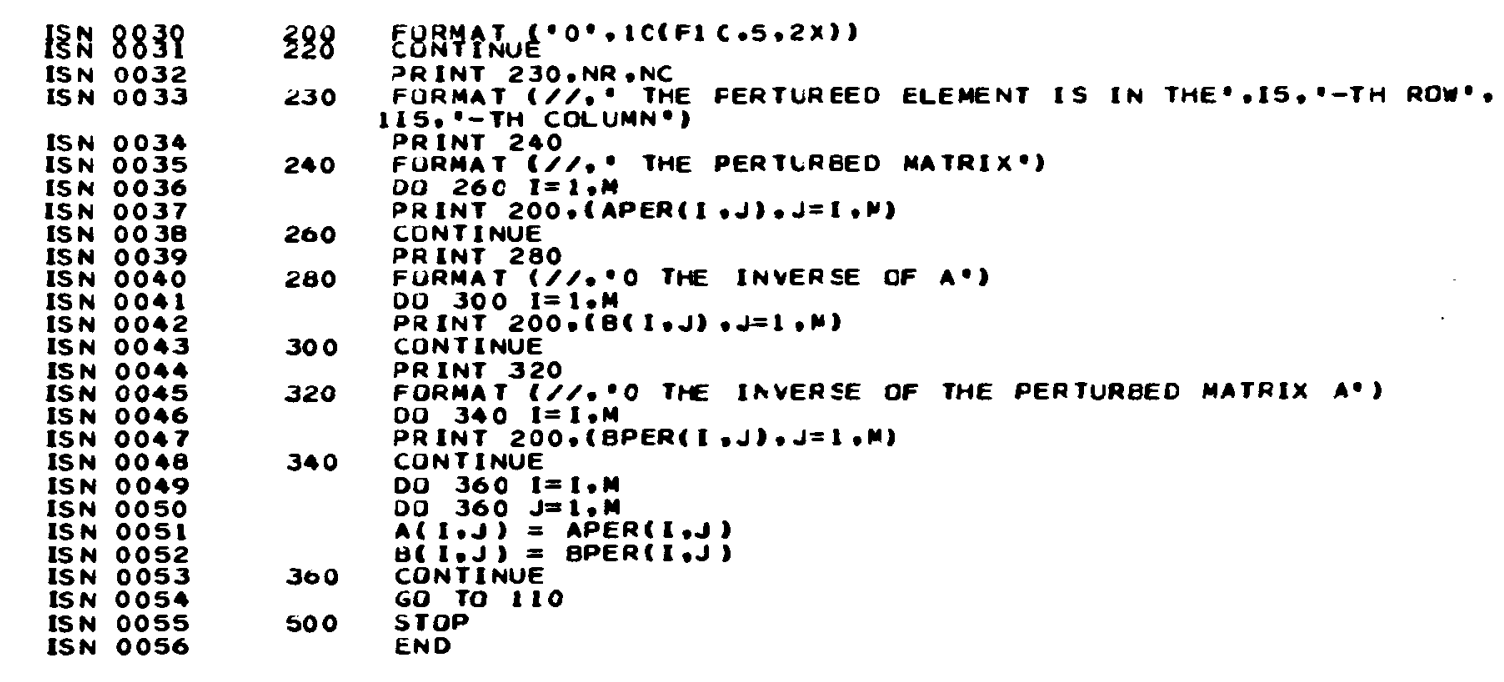




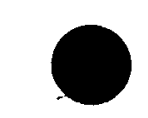


APPENDIX B 


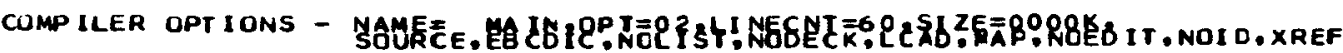

$$
\begin{aligned}
& C \\
& C \\
& C \\
& C \\
& C \\
& C \\
& C \\
& C \\
& \\
& C \\
& C \\
& C \\
& 1 \\
& 20 \\
& \\
& 40 \\
& C \\
& C \\
& C \\
& C \\
& C
\end{aligned}
$$

APPENOIX XYIA COM LIES THE INUERSE OF THE MATRIX IN EXAMPLE

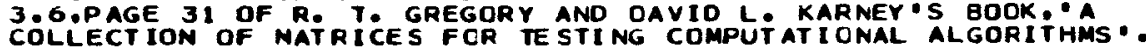

ISN 0002

ISN 0004

SN 0006

ISN 0008

IS N 0009

ISN 0010

ISN 0011

ISN OO13

ISN OO14

ISN 0018

IS 0022

ISN 0024

IS $\mathrm{N} 0025$

ISN 0026

ISN

ISN 0029

ISN 0030

ISN 0031

ISN 0033

ISN 0035

ISN 0036

ISN 0037

ISN O0J3

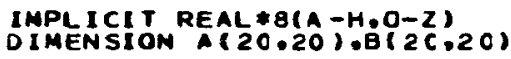

REAO N. THE DIMENSION CF $A$.

READ $(5,20 . E N D=5 O C) N$

FORMAT (IS)

DO $40 \mathrm{~J}=1 . \mathrm{N}^{2}$

$A(I B J)=N-\operatorname{CABS}(1-7)$

COMPUTE B, the IN IERSE OF A.

$R=1 \% 3$.

DO $60 \quad I=1 \cdot N$

IJ = (ABSi

IF ((I.EO.J) AAND. ((I.GT.1),AND.(I.LT.NI)) B(I.J) $=1$.

IF (IJ OEO.1) $A A N D \cdot(N \cdot N E \cdot 2) ; B(I, J)=-.5$

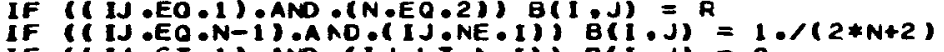

60

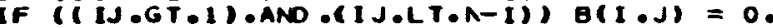

B(1.1) DFLOAT(N+2) COFLOAT(2*N+2)

B(NON) = B(1.1)

80

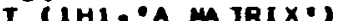

DO $120 \quad I=1, N$

PRINT 100 : i $(A(I, J), j=1, N)$

100
120

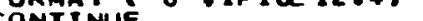

140

- OTHE INVERSE OF $A$

PRINT $100, i B(1, J), J=1, N)$

160

500

CONTINUE

STOP 


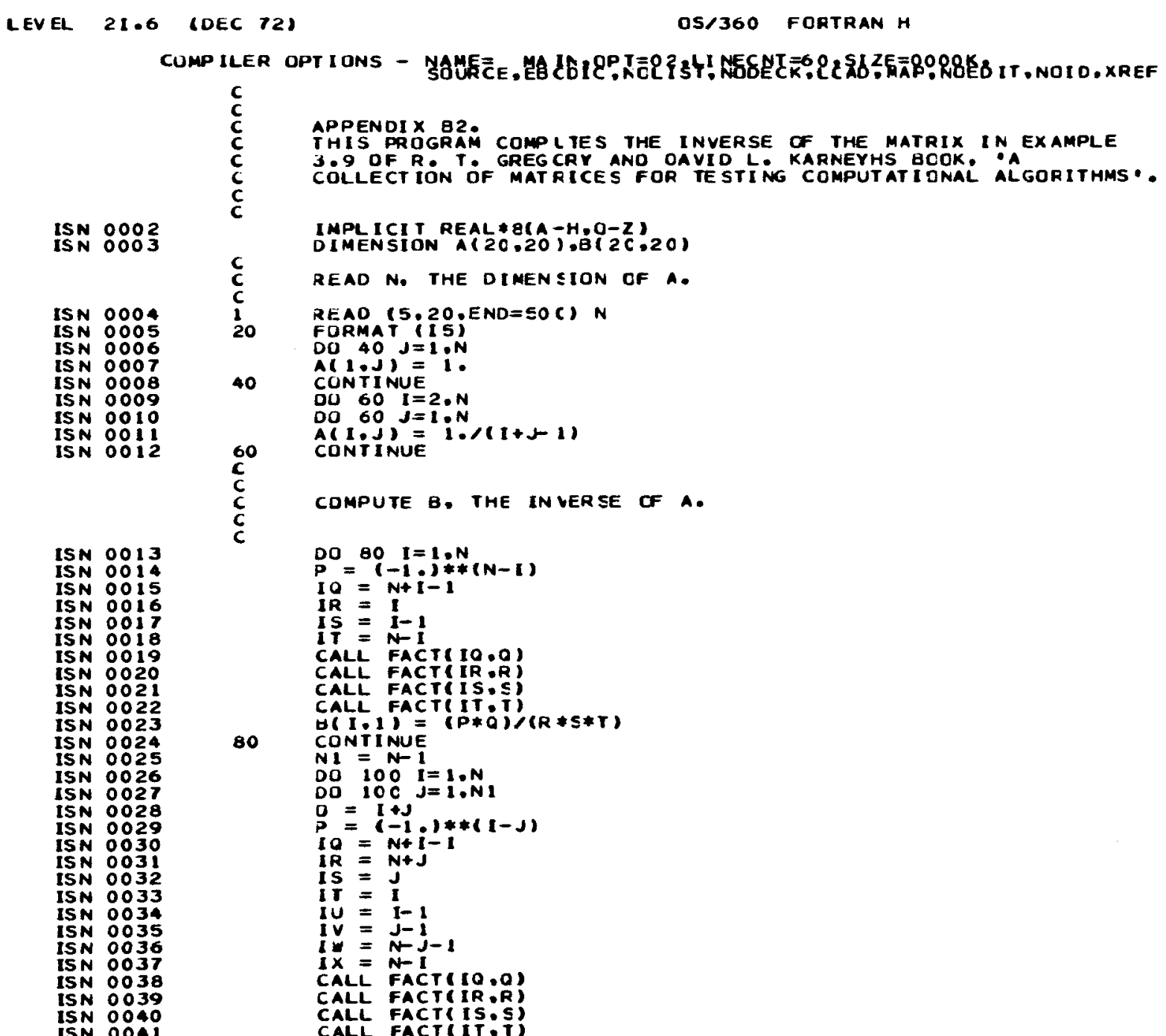




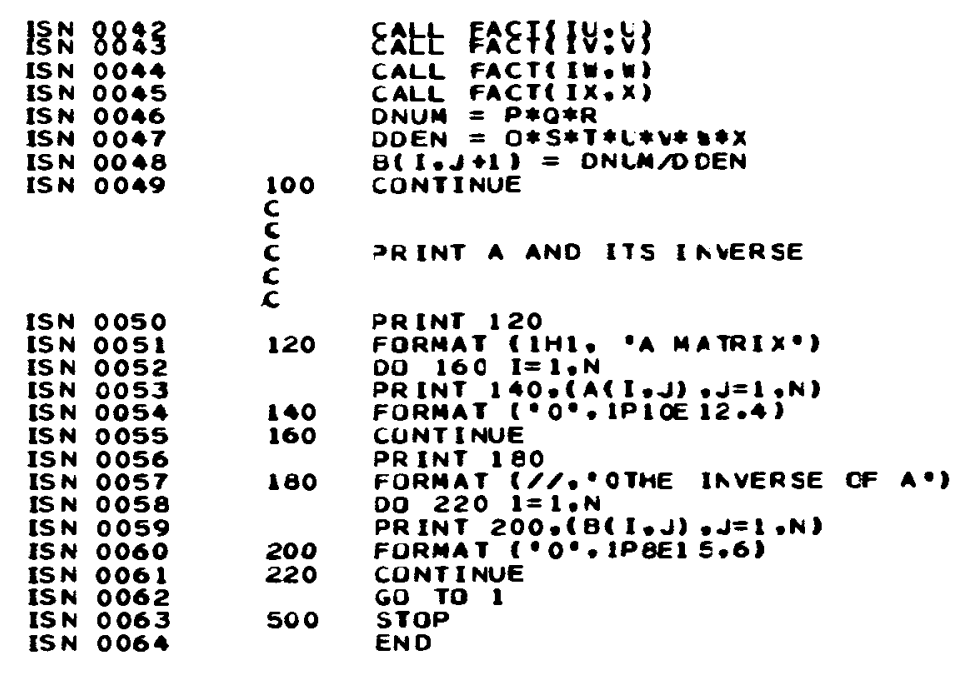




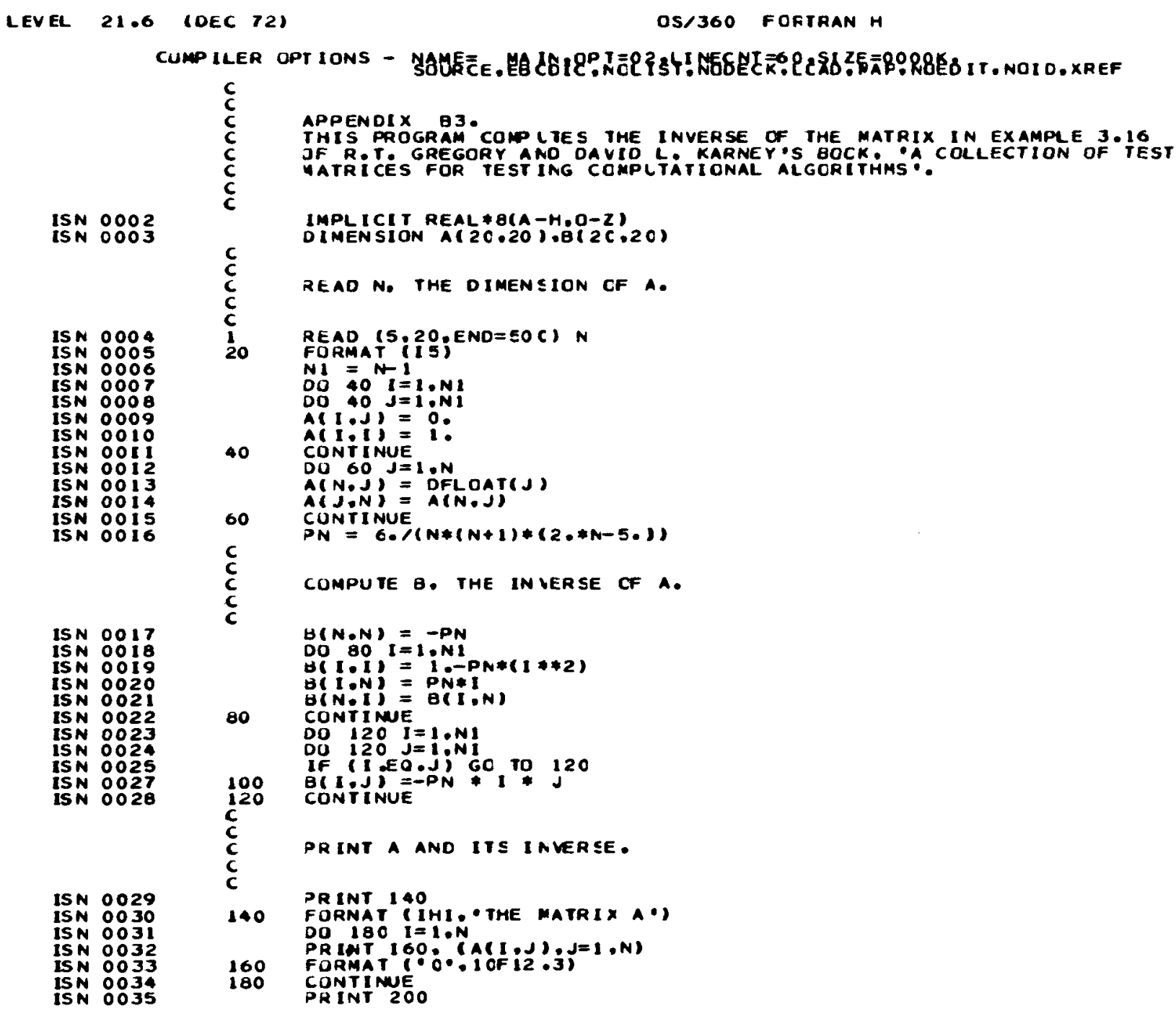

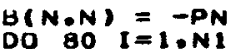

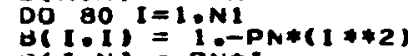

$B(1, N) \equiv P N=1 N$

80

DO $120 \mathrm{I=1} \cdot \mathrm{N1}$

IF IIEO.JiNGO TO 120

100 CONTINUE

pRINT A AND ITS IAVERSE.

C PRINT 140

140 FORNAT (IHI. THE MATRIXA.)

DO $1801=1 . N$

160 PRIAT 160: (AA(I,J):Ji, N)

180 FORTINUE 


\begin{tabular}{|c|c|c|}
\hline $\begin{array}{l}\text { ISN } 8836 \\
\text { ISN } 8837 \\
\text { ISN } 0038 \\
\text { ISN } 0039 \\
\text { ISN } 0040 \\
\text { ISN } 0041 \\
\text { ISN } 0042 \\
\text { ISN } 0043\end{array}$ & $\begin{array}{l}200 \\
220 \\
240 \\
500\end{array}$ & 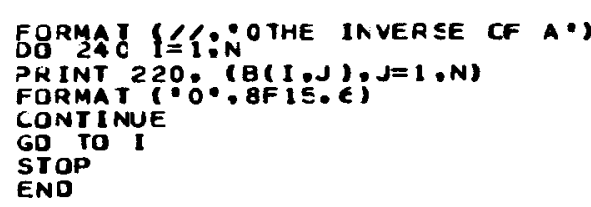 \\
\hline
\end{tabular}




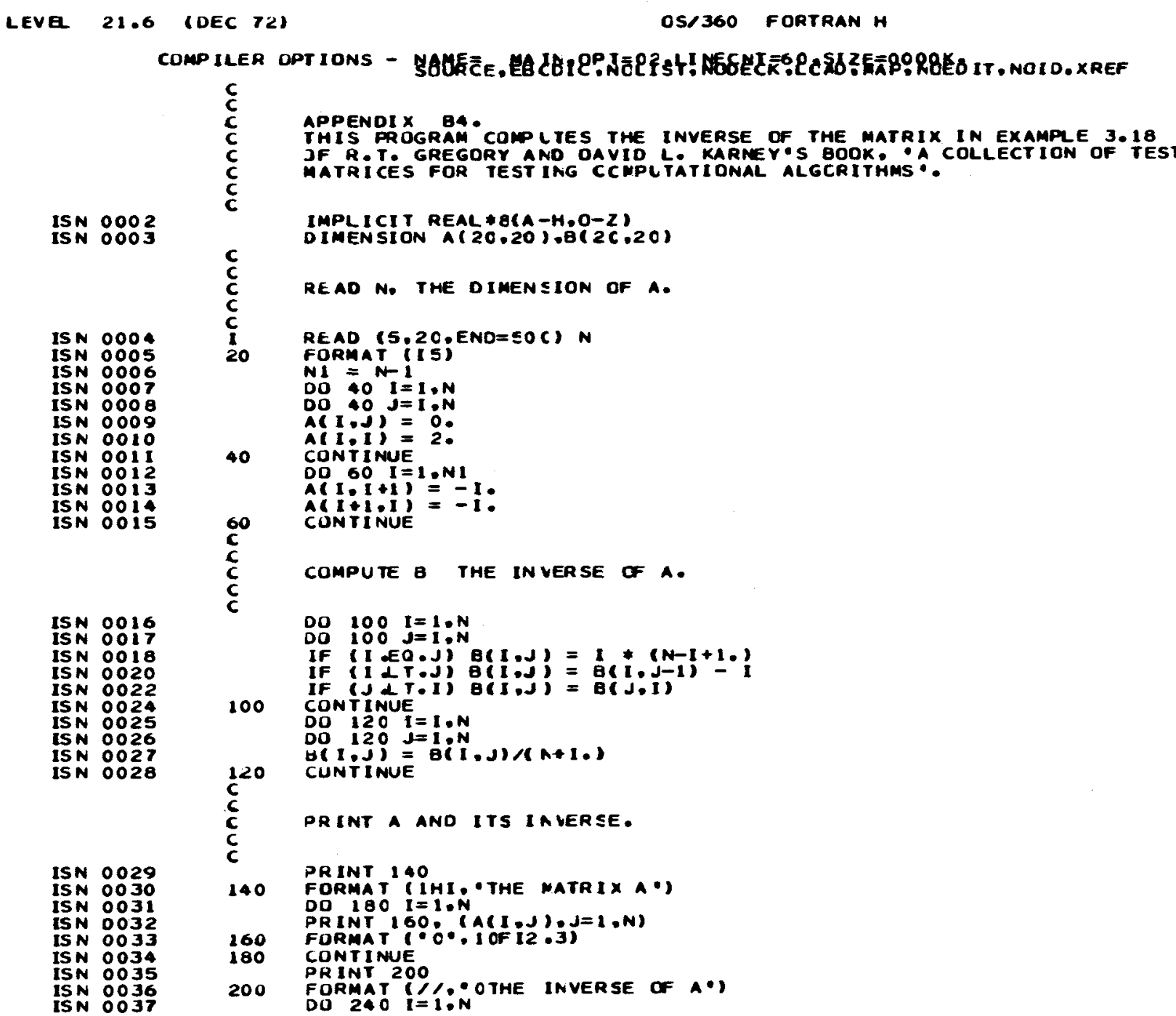

品 $1000 \mathrm{I}=1 ; 0 \mathrm{~N}$

IF (I IEO

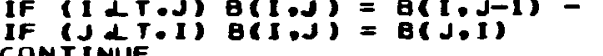

CONTINUE $1=I 0 N$

$\forall(1, J)=B(I, J) /(N+1$.

CUNTINUE

PRINT A AND ITS IAVERSE.

ISN 0029

ISN 0031

ISN 00032

ISN 0034

ISN 0035

ISN :0036

PRINT 140

140 FORMAT (IHI..THE MATRIXA.)

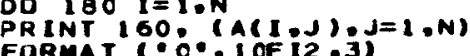

180 CONTINUE

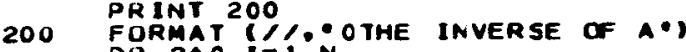


ISN 8838

ISN 0040

IS N 0042

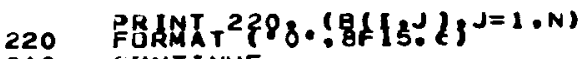

240 CUNIINUE

500 STOP 


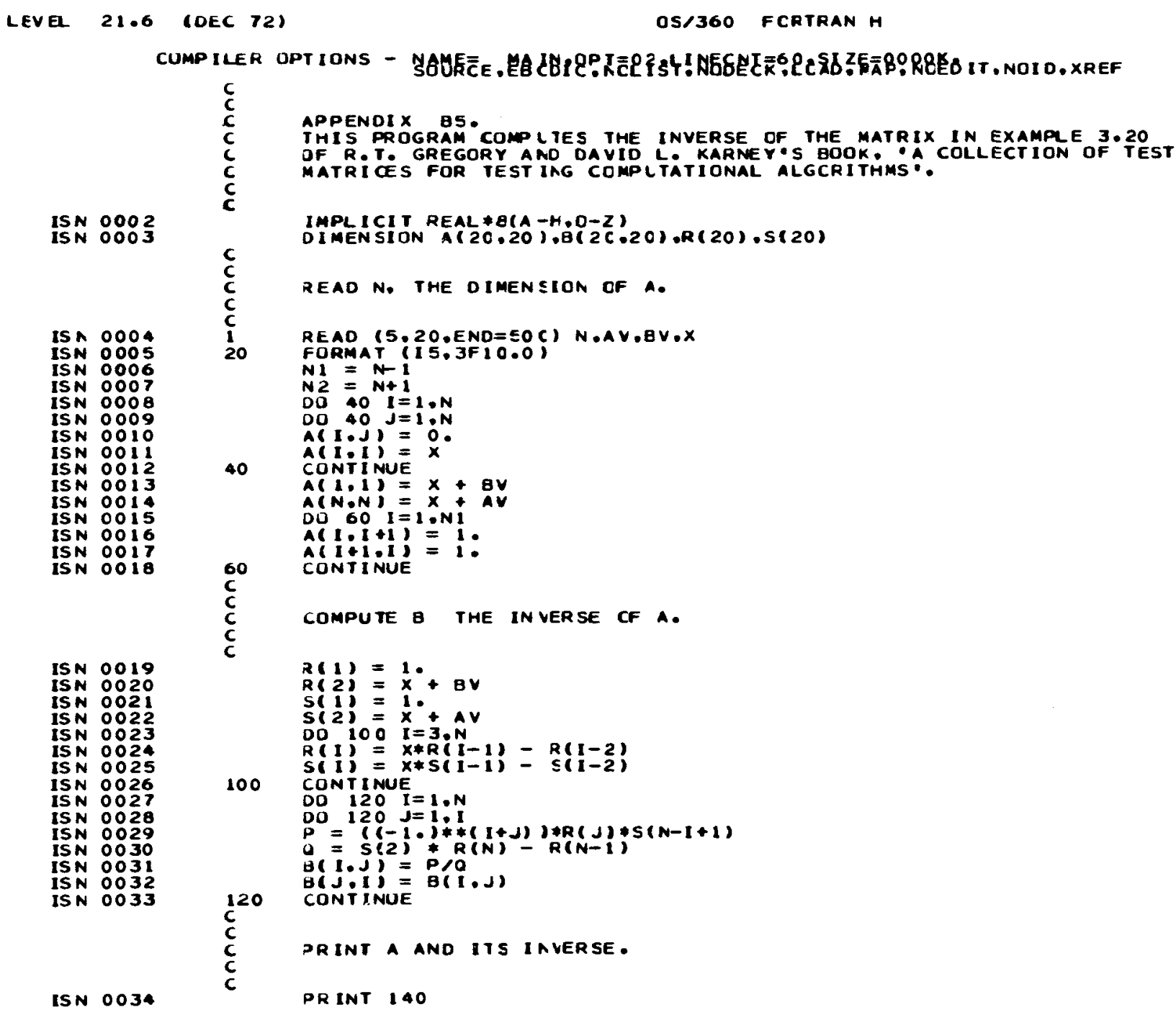

ISN 0034 IMPLICIT REAL $\#$ B (A -H.O-Z)

PR INT 140 


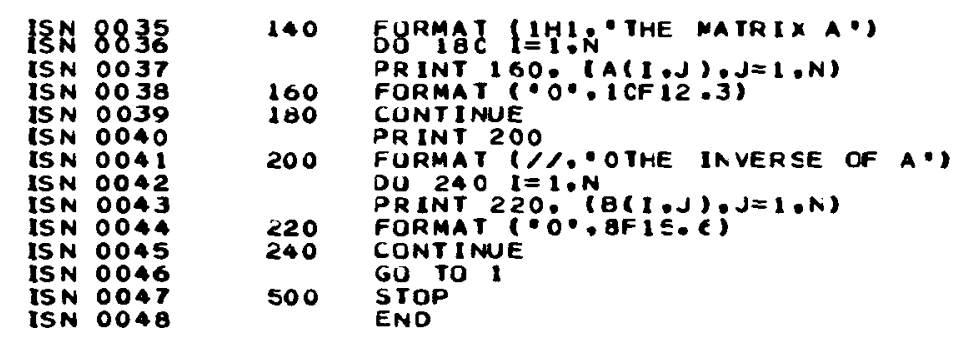




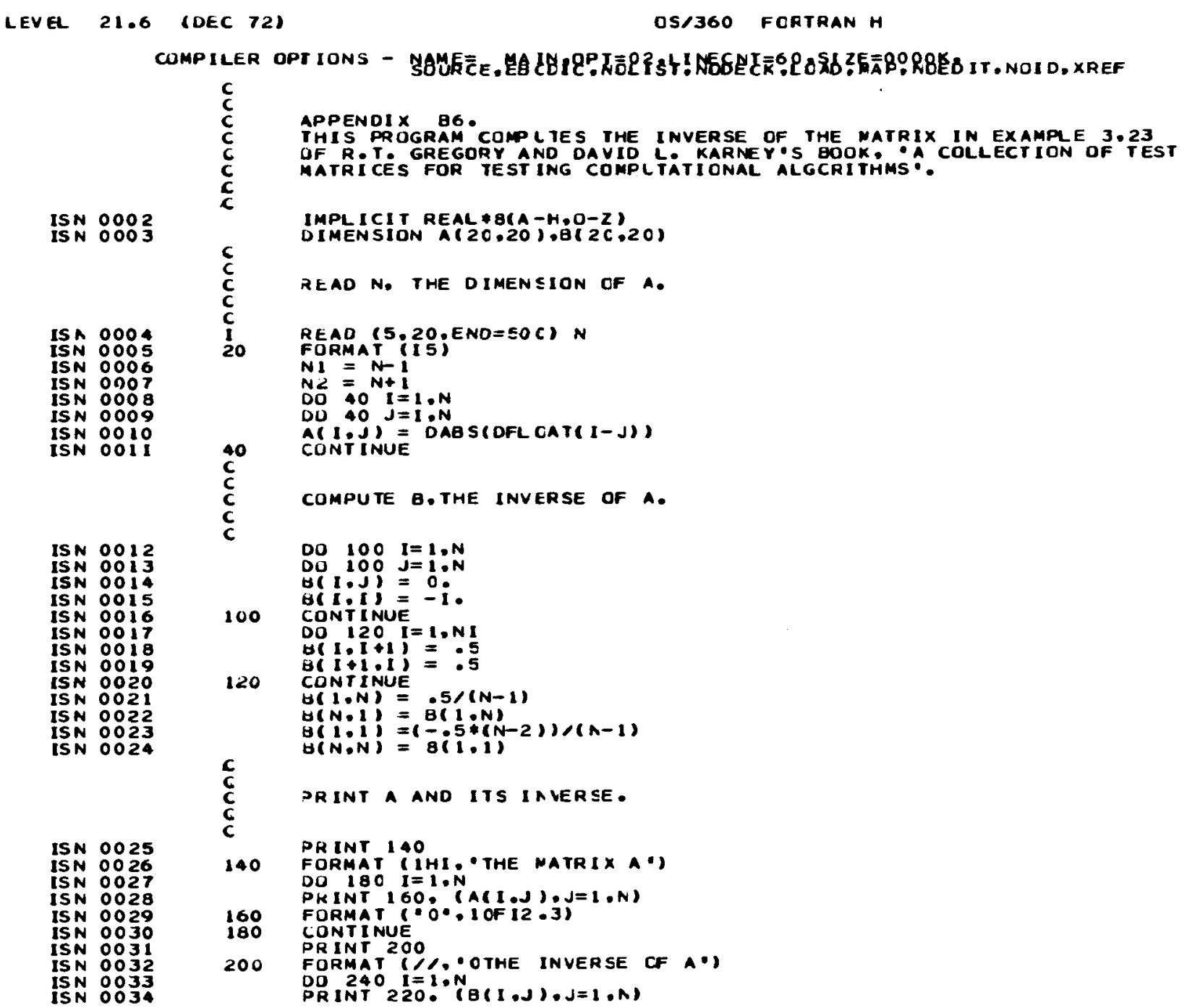


ISN 8835

IIN $\because 037$

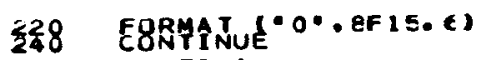

GU TO 1

END 


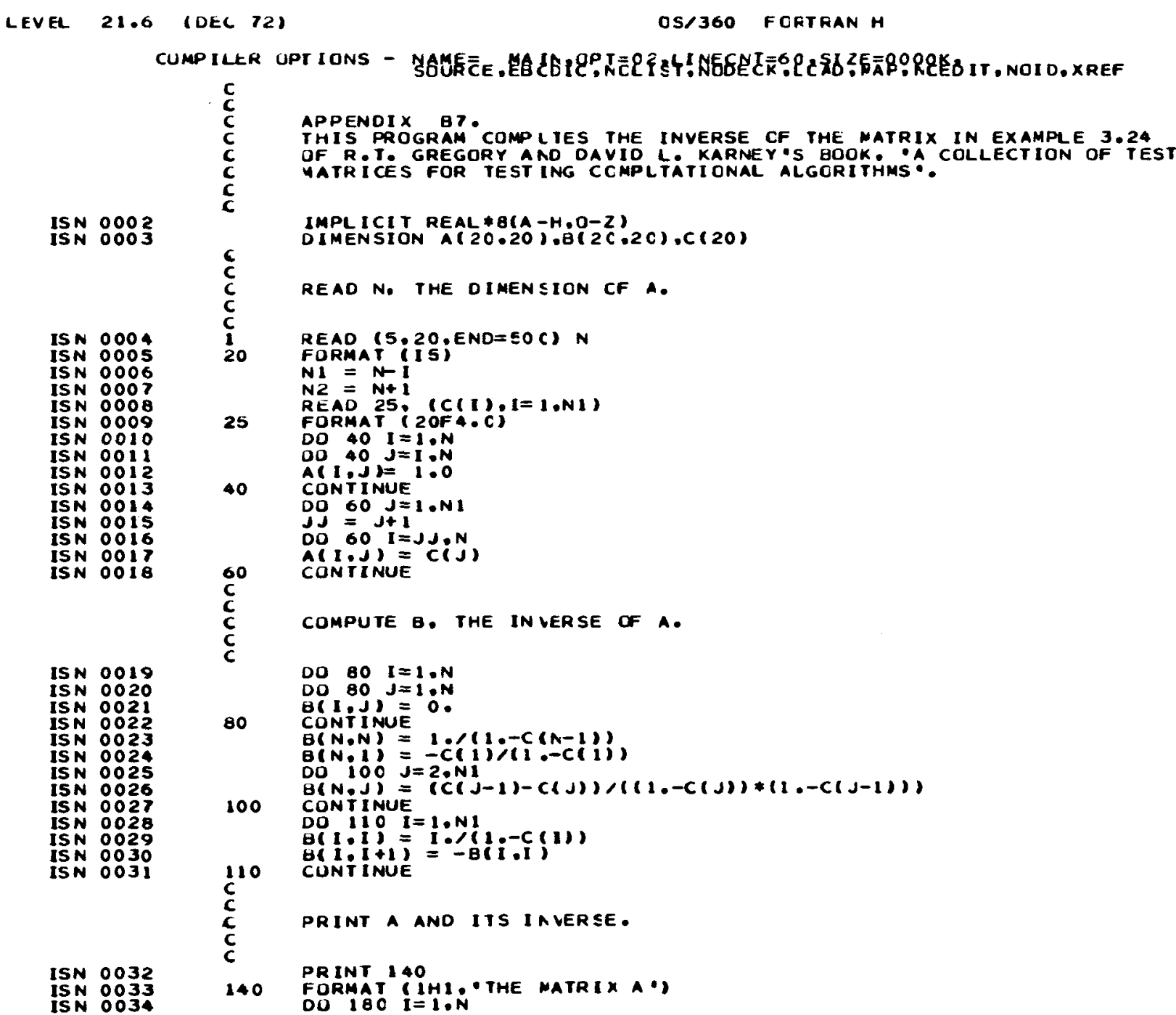




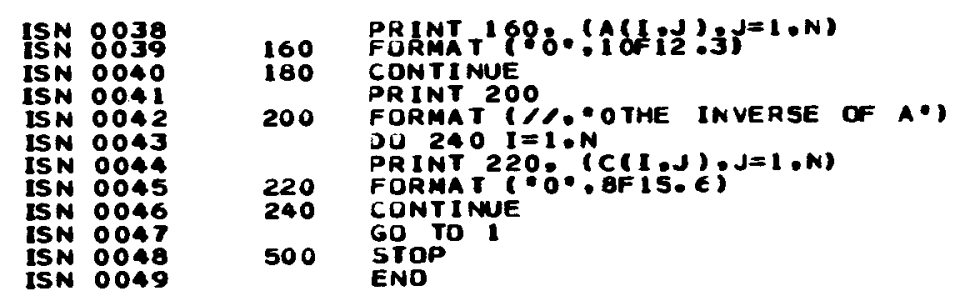




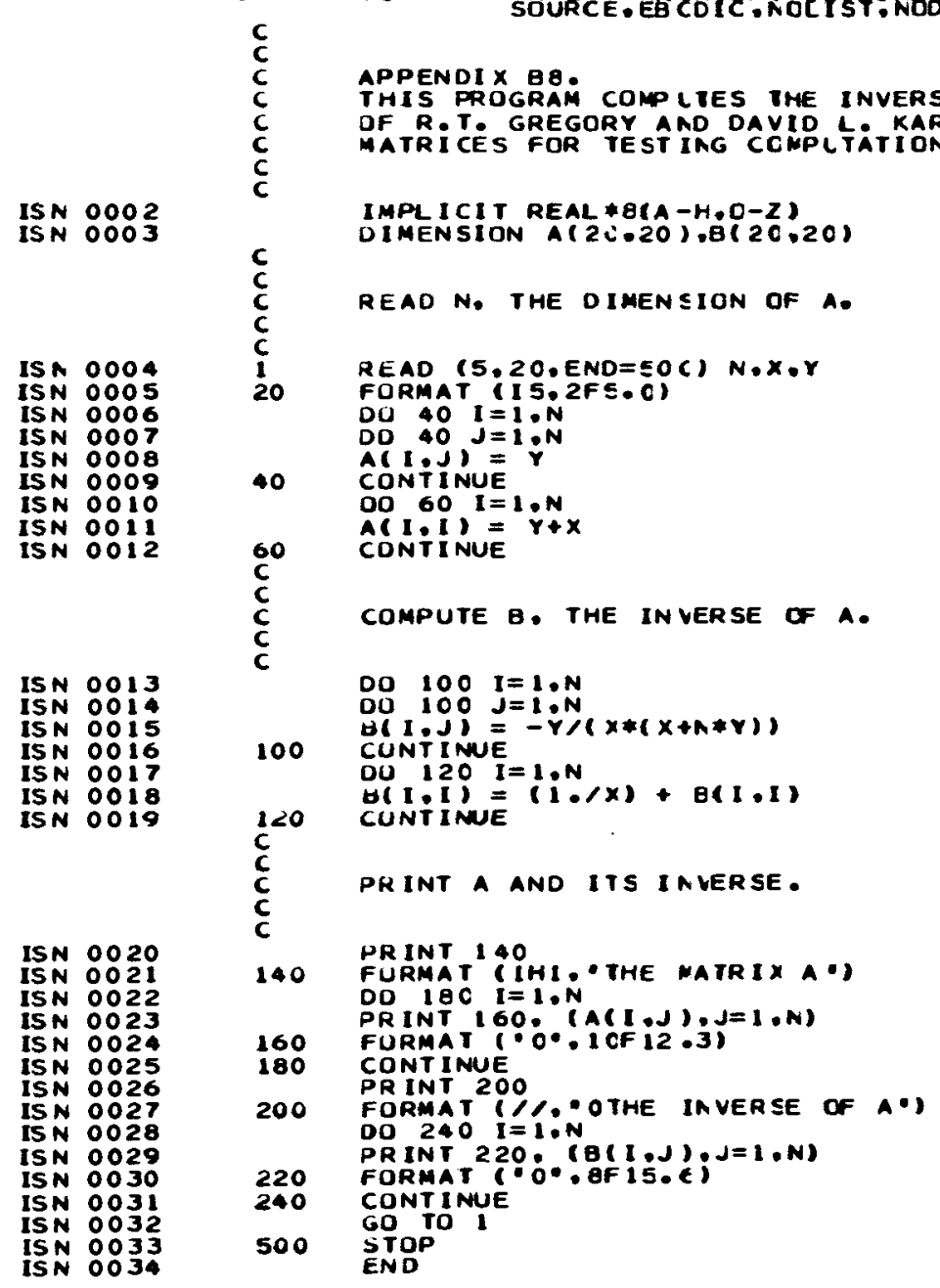




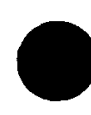


INTERNAL DISTRIBUTION

ORNL/CSD- 2

$\mathrm{UC}-32$

1-2. Central Research Library

3. Document Reference Section

4-6. Laboratory Records

7. Laboratory Records - RC

8. Computer Sciences Division Library

9. ORNL Patent Office

10. C. L. Allen

11. S. I. Auerbach

12. J. A. Auxier

13. J. A. Barker

14. C. K. Bayne

15. J. J. Beauchamp

16. M. Bender

17. C. J. Borkowski

18. K. O. Bowman

19. J. T. Bradbury

20. A. A. Brooks

21. J. M. Case

22. J. F. Clarke

23. H. P. Carter

24. S. J. Chang

25. R. R. Coveyou

26. J. A. Cox

27. F. L. Culler, Jr .

28. G. G. Fee

29. D. E. Ferguson

30. W. E. Fulkerson

31. D. A. Gardiner

32. D. G. Gosslee

33. L. J. Gray

34. W. 0. Harms
35. R. F. Hibbs

36. G. R. Jasny

37. P. R. Kasten

38. 0. L. Keller

39. W. E. Lever

40. R. S. Livingston

41. F. C. Maienschein

42. H. F. McDuffie

43. F. L. Miller, Jr.

44. T. J. Mitchel1

45. C. J. Parks

46. H. Postma

47. C. R. Richmond

48. M. W. Rosenthal

49. H. E. Seagren

50. P. H. Stelson

51. J. B. Storer

52. J. G. Sullivan

53. R. A. Tannert

54. D. B. Trauger

55-64. V. R. R. Uppuluri

65. P. R. Vanstrum

66. R. C. Ward

67. J. R. Weir

68. J. C. White

69. W. J. Wilcox

70. M. K. Wilkinson

71. R. A. Winke1

72. D. G. Wilson

73. C. D. Zerby

74. A. Zucker

\section{EXTERNAL DISTRIBUTION}

75. P. M. Anselone, Mathematics Department, Oregon State University, Corvallis, OR 97330

76. Ivo Babuska, Institute for Fluid Dynamics and Applied Mathematics, University of Maryland, College Park, MD 20742

77. James Baker, Mathematics and Computing B1dg. 50-A, Room 1140, Lawrence Berkeley Laboratory, University of California, Berkeley, CA 94720

78. Erwin H. Bareiss, Department of Computer Sciences and Engineering Sciences, Northwestern University, Evanston, IL 60201

79. L. Barrett, Department of Mathematics, University of Tennessee, Knoxville, TN 37916 
80. Richard Bellman, University of Southern California, University Park, Los Angeles, CA 90007

81. Garrett Birkhoff, Department of Mathematics, Harvard University, 2 Divinity Avenue, Cambridge, MA 02138

82. Charles E. Carter, U.S. Energy Research and Development Administration, Washington, DC 20767

83. John S. Coleman, National Academy of Sciences, National Research Council, 2101 Constitution Avenue, Washington, DC 20418

84. George B. Dantzig, Department of Operations Research, Stanford University, Stanford, CA 94305

85. C. W. Edington, U.S. Energy Research and Development Administration, Washington, DC 20767

86. Gerald Estrin, Department of Engineering, University of California, Los Angeles, CA 90024

87. Sidney Fernbach, Computation Division, Lawrence Livermore Laboratory, P. 0. Box 808, Livermore, CA 94550

88. Michae1 J. Flynn, Department of Computer Sciences, Johns Hopkins University, Baltimore, MD 21218

89. Paul Garabedian, ERDA Computing and Applied Mathematics Center, Courant Institute of Mathematical Sciences, New York University, 251 Mercer Street, New York, NY 10012

90. C. W. Gear, Department of Computer Science, University of Illinois, Urbana, IL 61803

91. Gene H. Golub, Computer Science Department, Stanford University, Stanford, CA 94305

92. H. Hollister, U.S. Energy Research and Development Administration, Washington, DC 20545

93. B. E. Hubbard, Institute for Fluid Dynamics and Applied Mathematics, University of Maryland, College Park, MD 20742

94. H. B. Keller, Applied Mathematics, California Institute of Technology, Pasadena, CA 91109

95. Peter D. Lax, Director, Courant Institute of Mathematical Sciences, New York University, New York, NY 10012

96. Erastus H. Lee, Department of Applied Mechanics, Stanford University, Stanford, CA 94305

97. J. L. Liverman, U.S. Energy Research and Development Administration, Washington, DC 20545

98. Clair G. Maple, Mathematics and Computer Division, Ames Laboratory, Iowa State University, Ames, IA 50010

99. Sidney Marks, Division of Biomedical and Environmental Research, U.S. Energy Research and Development Administration, Washington, DC 20545

100. William R. McSpadden, Theory and Analyses, Battelle Memorial Institute, Pacific Northwest Laboratory, P. 0. Box 999, Richland, WA 99352

101. Nicholas Metropolis, Room C-6, Los Alamos Scientific Laboratory, University of California, P. O. Box 1663, Los Alamos, NM 87544

102. M. E. Rose, Mathematical and Computer Sciences Program, Molecular Sciences and Energy Research, Division of Physical Research, U.S. Energy Research and Development Administration, Washington, DC 20545 
103. J. Barkley Rosser, University of Wisconsin, Mathematics Research Center, Madison, WI $\mathbf{5 3 7 0 6}$

104. Richard J. Royston, Applied Mathematics Division, Argonne National Laboratory, 9700 South Cass Avenue, Argonne, IL 60439

105. L. R. Shenton, Computing Center, University of Georgia, Athens, GA 30601

106. Yoshio Shimamoto, Applied Mathematics Department, Brookhaven National Laboratory, Upton, Long Island, NY 11973

107. Gustavus J. Simmons, Department of Mathematics and Computer Science, Sandia Laboratories, P. O. Box 5800 Albuquerque, NM 87115

108. Milton Sobe1, Department of Statistics, University of Minnesota, Minneapolis, MN 55455

109. Daniel L. Solomon, Biometrics Unit, Cornell University, Warren Hal1, Ithaca, NY 14850

110. John W. Tukey, Department of Statistics, Princeton University, Princeton, NJ 03540

111. Richard S. Varga, Department of Mathematics, Kent State University, Kent, $\mathrm{OH} 44240$

112. Gordon L. Walker, American Mathematical Society, 321 South Main Street, P. 0. Box 6245, Providence, RI 02904

113. G. S. Watson, Department of Statistics, Princeton University, Princeton, NJ 08540

114. A. M. Weinberg, Institute of Energy Analyses, c/o Oak Ridge Associated Universities, P. O. Box 117, Oak Ridge, TN 37830

115. Research and Technical Support Division ERDA, ORO

116-273. Given distribution as shown in TID-4500 under Mathematics and Computers (25 copies - NTIS). 